\title{
Distributions of Spinothalamic, Spinohypothalamic, and Spinotelencephalic Fibers Revealed by Anterograde Transport of PHA-L in Rats
}

\author{
Kenneth D. Cliffer, ${ }^{a}$ Rami Burstein, ${ }^{\mathrm{b}}$ and Glenn J. Giesler, Jr. \\ Department of Cell Biology and Neuroanatomy, University of Minnesota, Minneapolis, Minnesota 55455
}

\begin{abstract}
Fibers projecting from several levels of the spinal cord to the diencephalon and telencephalon were labeled anterogradely with Phaseolus vulgaris leucoagglutinin injected iontophoretically. Labeled fibers in the thalamus confirmed projections previously observed. In addition, many labeled fibers were seen in the hypothalamus and in telencephalic areas not generally recognized previously as receiving such projections. In the hypothalamus, these areas included the lateral hypothalamus (including the medial forebrain bundle), the posterior hypothalamic area, the dorsal hypothalamic area, the dorsomedial nucleus, the paraventricular nucleus, the periventricular area, the suprachiasmatic nucleus, and the lateral and medial preoptic areas. In the telencephalon, areas with labeled fibers included the ventral pallidum, the globus pallidus, the substantia innominata, the basal nucleus of Meynert, the amygdala (central nucleus), the horizontal and vertical limbs of the diagonal band of Broca, the medial and lateral septal nuclei, the bed nucleus of the stria terminalis, the nucleus accumbens, infralimbic cortex, and medial orbital cortex. These results suggest that somatosensory, possibly including visceral sensory, information is carried directly from the spinal cord to areas in the brain involved in autonomic regulation, motivation, omotion, attention, arousal, learning, memory, and sensory-motor integration. Many of these areas are associated with the limbic system.
\end{abstract}

Somatic, including visceral, stimuli can elicit multifaceted responses and experiences involving many parts of the brain. The spinal cord is the area of the CNS through which most information about such stimuli from the body is conveyed to the brain. Pathways carrying such information from the spinal cord to areas in the hypothalamus and telencephalon have been generally considered to be indirect, synapsing at least once before

\footnotetext{
Received Aug. 13, 1990; reviscd Oct. 22, 1990; accepted Nov. 2, 1990.

This work was supported by NIH Grant NS25932. K.D.C. was supported in part by NIDA Training Grant DA07234. We thank Mr. G. Sedgewick for help with phutography, Ms. C. Audersen and Mr. H. Truong for technical assistance, Dr. J. Katter for technical assistance and comments on the manuscript, and Drs. W. D. Willis and R. J. Dado for comments on the manuscript.

Correspondence should be addressed to Glenn J. Giesler, Jr., Department of Cell Biology and Neuroanatomy, University of Minnesota, 4-123 Jackson Hall, 321 Church Street SE, Minneapolis, MN 55455.

Present address: Marine Biomedical Institute, The University of Texas Medical Branch, Galveston, TX 77550-2772.

- Present address: The Pain Physiology Laboratory, Neurology Service, Massachusetts General Hospital, and the Neuroscience Program, Harvard Medical School, Boston, MA 02114.

Copyright (c) 1991 Society for Neuroscience $0270-6474 / 91 / 110852-17 \$ 03.00 / 0$
}

they reach these levels (e.g., Lumb and Wolstencroft, 1985; Werner and Bienek, 1985; Swanson, 1987; Kai et al., 1988; Ma and Peschanski, 1988). Recently, we reported that cells in the spinal cord project directly to the hypothalamus and to several telencephalic areas (Burstein et al., 1987, 1990a; Burstein and Giesler, 1989). Cells in the lumbar enlargement of the spinal cord that project to the hypothalamus respond preferentially to noxious input (Burstein et al., 1987). The size of the spinohypothalamic tract in rats rivals that of the spinothalamic tract (Burstein et al., 1990a,c), a pathway that has been considered one of the major pathways ascending from the spinal cord to the brain. Spinotelencephalic pathways appear to be smaller but still substantial (Burstein and Giesler, 1989). The present report describes the results of our experiments using anterograde transport of Phaseolus vulgaris leucoagglutinin (PHA-L) to determine areas in the diencephalon and telencephalon to which cells in the spinal cord project.

\section{Materials and Methods}

The techniques for injection of PHA-L and subsequent processing and analysis of results were essentially as reported previously (Cliffer and Giesler, 1989). Brieffy, male Sprague-Dawley rats, between 280 and 450 gm (Biolab Corp., St. Paul, MN), were deeply anesthetized with sodium pentobarbital (i.p., supplemented when necessary with additional sodium pentobarbital or with sodium methohexital). A laminectomy allowed iontophoretic injection of a $2.5 \%$ solution of PHA-L (Gerfen and Sawchenko, 1984) in sodium PBS (pH, 7.2). Multiple injections were made through glass micropipettes with tip diameters of 10-15 $\mu \mathrm{m}$ (5 $\mu \mathrm{A}$, pulsed $8 \mathrm{sec}$ on, $2 \mathrm{sec}$ off for a total of $40 \mu \mathrm{A}$-min each injection). Nine to thirty-five injections were made in 1-4 transverse planes, separated by no more than $0.5 \mathrm{~mm}$. Table 1 shows the numbers and locations of injections in 7 cases. Cases CE-2 and CE-4 (illustrated in Figs. 2, 3, respectively) each received a total of 30 injections in 3 planes within the cervical enlargement.

After survival periods of up to $41 \mathrm{~d}$ after injection of PHA-L (Table 1), animals were deeply anesthetized and perfused with Tyrode's solution, followed by $4 \%$ paraformaldehyde $(\mathrm{pH}, 6.5)$, then $4 \%$ paraformaldehyde with $0.05 \%$ glutaraldehyde ( $\mathrm{pH}, 9.4$; Berod et al., 1981). Tissue was postfixed $12-24 \mathrm{hr}$ in the high-pH fixative solution. After postfixation, tissue was stored in $10 \%$ sucrose in Sorenson's phosphate buffer $(\mathrm{pH}, 7.2)$. The medulla and spinal cord were cut at 20 or $30 \mu \mathrm{m}$ on a freezing microtome in either the horizontal or the transverse plane. Sections were taken at intervals of 30-150 $\mu \mathrm{m}$.

PHA-L was immunohistochemically labeled in floating sections using the avidin-biotin fluorescence technique (using fuorescein isothiocyanate as the fluorophore; reagents from Vector Laboratories, Inc., Burlingame, CA). After mounting, sections were counterstained with ethidium bromide (Schmued et al., 1982) and coverslipped using an antifade medium containing phenylenediamine (Johnson and de C. Nogueira Araujo, 1981).

Fluorescent material was examined microscopically using reflected illumination. Photomicrographs of fluorescein-labeled fibers were made using a 560-nm short-pass barrier filter to enhance contrast with back- 
Table 1. Basic information and areas in which labeled fibers were found in the diencephalon and telencephalon for 7 cases

\begin{tabular}{|c|c|c|c|c|c|c|c|}
\hline & \multicolumn{7}{|l|}{ Case } \\
\hline & CE-1 & CE-2 & CE-3 & CE-4 & CE-5 & TH-1 & LE-1 \\
\hline Injection level & $\mathrm{C} 8 / \mathrm{T} 1$ & $\mathrm{C} 7 / 8$ & $\mathrm{C} 8 / \mathrm{T} 1$ & C6 & $\mathrm{T} 1$ & $\mathrm{~T} 10$ & $\mathrm{~L} 3 / 4$ \\
\hline Plane of sectioning & $\mathrm{T}$ & $\mathrm{T}$ & $\mathrm{T}$ & $\mathrm{H}$ & $\mathbf{H}$ & $\mathrm{H}$ & $T$ \\
\hline Number of injections & 9 & 30 & 30 & 30 & 30 & 30 & 26 \\
\hline Survival time (days) & 21 & 21 & 20 & 21 & 40 & 36 & 35 \\
\hline Distance between sections $(\mu \mathrm{m})$ & 150 & 60 & 60 & 30 & 40 & 40 & 60 \\
\hline \multicolumn{8}{|l|}{ Thalamus } \\
\hline Ventrobasal & * & $*$ & $*$ & $*$ & $*$ & $*$ & * \\
\hline Posterior & $*$ & $*$ & * & $*$ & $*$ & & * \\
\hline Intralaminar & $*$ & $*$ & * & $*$ & $*$ & $*$ & * \\
\hline Midline & $*$ & * & $*$ & $*$ & $*$ & $*$ & $*$ \\
\hline Mediodorsal & & $*$ & $*$ & $*$ & & & \\
\hline Habenula & & $*$ & $*$ & & & 、 & \\
\hline \multicolumn{8}{|l|}{ Hypothalamus } \\
\hline Medial & $*$ & $*$ & $*$ & $*$ & * & $*$ & * \\
\hline Lateral & $*$ & * & $*$ & $*$ & $*$ & * & $*$ \\
\hline Supraoptic decussation & $*$ & $*$ & $*$ & $*$ & $*$ & $*$ & * \\
\hline \multicolumn{8}{|l|}{ Telencephalon } \\
\hline VP, SI, BST, HDB,VDB, B & $*$ & * & * & $*$ & * & * & $*$ \\
\hline Septum & & & & & & & \\
\hline Medial & $*$ & & & & & & \\
\hline Latcral & $*$ & $*$ & $*$ & $*$ & & & \\
\hline Nucleus accumbens & $*$ & $*$ & * & & & & \\
\hline Globus pallidus & & * & $*$ & $*$ & & & \\
\hline Amygdala & $*$ & * & - & $*$ & & & \\
\hline Cortex & $*$ & $*$ & & $*$ & & & \\
\hline
\end{tabular}

Case numbers coded for levels of injections: CE, cervical enlargement; TH, thoracic; $L E$, lumbar enlargement. Planes of sectioning: $\mathrm{T}$, transverse; $\mathrm{H}$, horizontal. Symbols, *, labeled fibers present; - , structure not available. See Appendix for abbreviations of brain areas.

ground fluorescence. Dark-field illumination was used to determine architectonic boundaries, along with analysis based on the counterstained cells where necessary. The atlas of Paxinos and Watson (1986) was used for reference. Drawings were made using a camera lucida drawing attachment on the microscope.

\section{Results}

Injections

Figure 1 is a photomicrograph of a transverse section of the spinal cord stained for PHA-L, at the level of 9 injections in the cervical enlargement (case CE-1). We attempted to inject in all the regions in which we had previously found retrogradely labeled spinohypothalamic tract cells, including marginal zone, lateral reticulated area, the area around the central canal, and the lateral spinal nucleus (Burstein et al., 1987, 1990a). As noted previously (Cliffer and Giesler, 1989), in cases with the longest survival times the diffuse labeling in the gray matter at sites of injections was depleted, though some labeled cells usually remained and label was still present in the white matter.

\section{Iocations of labeled fibers}

We found the most extensive labeling in the diencephalon and telencephalon in 4 animals that survived for 20-21 d after injections in the cervical enlargement. Labeling appeared less extensive in 3 animals that survived from 34 to $40 \mathrm{~d}$ with injections also in the cervical enlargement, as well as in 4 animals with injections at more caudal levels ( 2 in lumbar enlargement, 2 in mid-thoracic cord) that survived from 27 to $41 \mathrm{~d}$. For 7 cases, the areas in which labeled fibers and varicosities were found in the diencephalon and telencephalon are listed in Table 1. These include the cases with the most extensive distributions of labeled elements after injections in the cervical enlargement, one case that was injected in thoracic spinal cord, and one case that was injected in the lumbar enlargement. Figures 2 and 3 show reconstructions of the distributions of the labeled fibers in transverse and horizontal sections in cases CE-2 and CE-4, respectively, that were injected in the cervical enlargement. Figures 4 and 5 contain photomicrographs of labeled fibers in various cases. Additional reconstructions of locations of labeled fibers in transverse sections from the most rostral parts of the brain are presented in Figures 6 and 7.

Labeled fibers in the midbrain were seen in the periaqueductal gray (PAG; Figs. $2 A-C, 3 J, K$ ), in the parabrachial area (Fig. $3 E-$ $K$, caudal), in deep mesencephalic areas (Figs. $2 A, B ; 3 G-J$ ), in the pretectum (Figs. $2 C-E, 3 I-K$ ), in the red nucleus (Fig. $3 E$ ), and in pars reticulata of the substantia nigra (Figs. $2 B, 3 E-G$, $4 A$ ). The labeling in the midbrain was largely bilateral.

Areas containing labeled fibers in the diencephalon included those previously recognized as receiving spinothalamic projections, including the area of the spinothalamic tract (laterally adjacent to the medial lemniscus; Figs. $2 A-E, 3 F-H)$, the posterior complex (Figs. $2 B-H, 3 I-J$ ), the ventrobasal complex (Figs. $2 F-H, 3 G-H$ ), the ventrobasal/ventrolateral border zone 
Figure 1. Photomicrograph of the injection site for case CE-1, at the level of 9 injections in a single transverse plane.

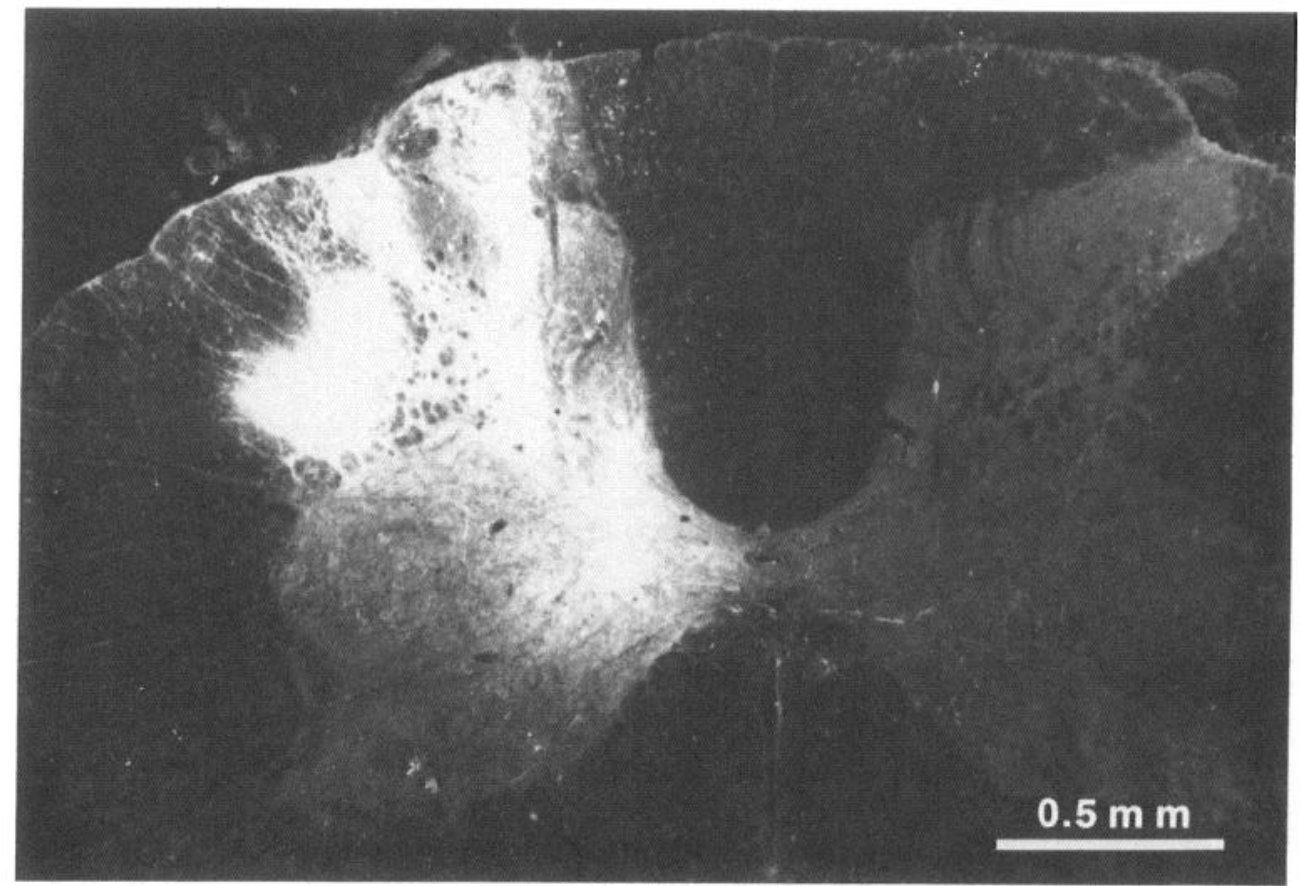

(Fig. $2 K$ ), the ventrolateral nucleus (Fig. $2 K, L$ ), the ventromedial nucleus (Fig. $2 G-J$ ), the intralaminar nuclei (parafascicular, Figs. $2 D-G, 3 I, J$; paracentral, Fig. $2 J, K$; central medial, Fig. $2 F, G$; centrolateral, Figs. $2 G, H ; 3 J, K)$, the mediodorsal nucleus (Fig. $2 H, L, M$ ), midline nuclei [paraventricular, Figs. $2 G-M$, $3 I, J$; reuniens, Figs. $2 G$ (ventral to central medial thalamic nucleus), $3 E$ (medial to nucleus submedius)], zona incerta (Figs. $2 F-I, 3 F, H$ ), and the habenula (Fig. $2 I, J$ ). Labeled fibers in the caudal part of the ventrobasal complex were seen after injections in either the cervical or lumbar enlargement. In case TH-1, with injections in thoracic cord, labeling in the rostral ventrobasal complex was in its lateral and dorsal part. This contrasts with the more ventral and medial location of labeled fibers in the rostral ventrobasal complex of case CE-2 (Fig. $2 K$ ), which was injected in the cervical enlargement. In one case, a labeled fiber (not illustrated) was seen to run a long distance in the stria medullaris thalami, between the level of the habenula and the most rostral level to which the tract could be followed. Very little labeling was found in nucleus submedius (Figs. $2 G-J, 3 G-$ $H$ ). Most of the labeling in the thalamus was contralateral to the injections, but bilateral labeling was observed, especially in the midline nuclei.

In addition, fibers were clearly labeled in areas that have not generally been recognized as projection sites for neurons with somata in the spinal cord. In the hypothalamus, these areas were in both the lateral hypothalamus (Figs. $2 C-M, 3 B-D$ ) and the medial hypothalamus, including the posterior hypothalamic area (Figs. $2 D, E ; 3 C-E$ ), the dorsal hypothalamic area (Figs. $2 F, G ; 3 F-H$ around the third ventricle), the dorsomedial hypothalamic nucleus (Fig. $2 G$ ), the paraventricular hypothalamic nucleus (Fig. $2 J, K$ ), the suprachiasmatic nucleus (Fig. $2 K$ ), and the medial and lateral preoptic areas (Fig. $2 M-P$ ). Many of the labeled fibers in the lateral hypothalamus were oriented in a caudal-rostral direction, running along with fibers of the medial forebrain bundle (Fig. 4B). These exhibited varicosities and branches, suggesting involvement in functional interactions in the lateral hypothalamus, even if they projected to more rostral levels. As was the case for the thalamus, labeled fibers in the hypothalamus were predominantly contralateral to the injections, but were observed on the ipsilateral side also, especially in the lateral hypothalamus.

Near the lateral and ventral limits of the hypothalamus, labeled fibers were observed bilaterally throughout the course of the supraoptic decussation, immediately dorsal, medial, and caudal to the optic tract and chiasm (Figs. $2 C-L, 3 A-F$ ). These fibers also tended to be more prevalent contralateral to the injection.

In the telencephalon, though labeled fibers were not as common as in the diencephalon (note numbers of sections mapped in Fig. 2), they were seen in many areas of the basal forebrain, including the ventral pallidum and substantia innominata (Figs. $2 L-V ; 3 C, D ; 4 D)$, the horizontal and vertical limbs of the diagonal band of Broca (Figs. $2 N-R, 3 B-D, 6 A, B$ ), and the bed nucleus of the stria terminalis (Figs. $2 N-Q, 3 F-H$, rostral and medial to the internal capsule). The amygdala (central nucleus; Figs. $2 H ; 3 C, D ; 5$ ) and globus pallidus (Figs. $2 M-O, 3 F-I$ ) both contained labeled fibers. Labeled fibers were also seen in the basal nucleus of Meynert (Figs. $2 K, M ; 3 E$, near the lateral part of the internal capsule, rostral to the optic tract). In one case (CE-1; Fig. 5), a stained fiber was seen in a transverse section running along the ventral border of the internal capsule and ventrally and laterally between the internal capsule and the amygdala (Fig. 5B). In an adjacent section, labeled fibers were seen within the amygdala (Fig. $5 C$ ).

Labeled fibers were also observed more rostrally, in the septal nuclei, nucleus accumbens, and cortical areas. In the medial septum, intensely labeled fibers in one case were seen adjacent to the midline (Figs. $4 E, 6 A, B$ ). The nucleus accumbens contained labeled fibers, mostly in its medial portion (Figs. $2 T-V$, $6 C$ ). Many of these were near labeled fibers in the adjacent lateral part of the lateral septum (Fig. 6C) or in the cortex, including infralimbic cortex (Fig. $2 U, V$ ). Some labeled fibers were also 

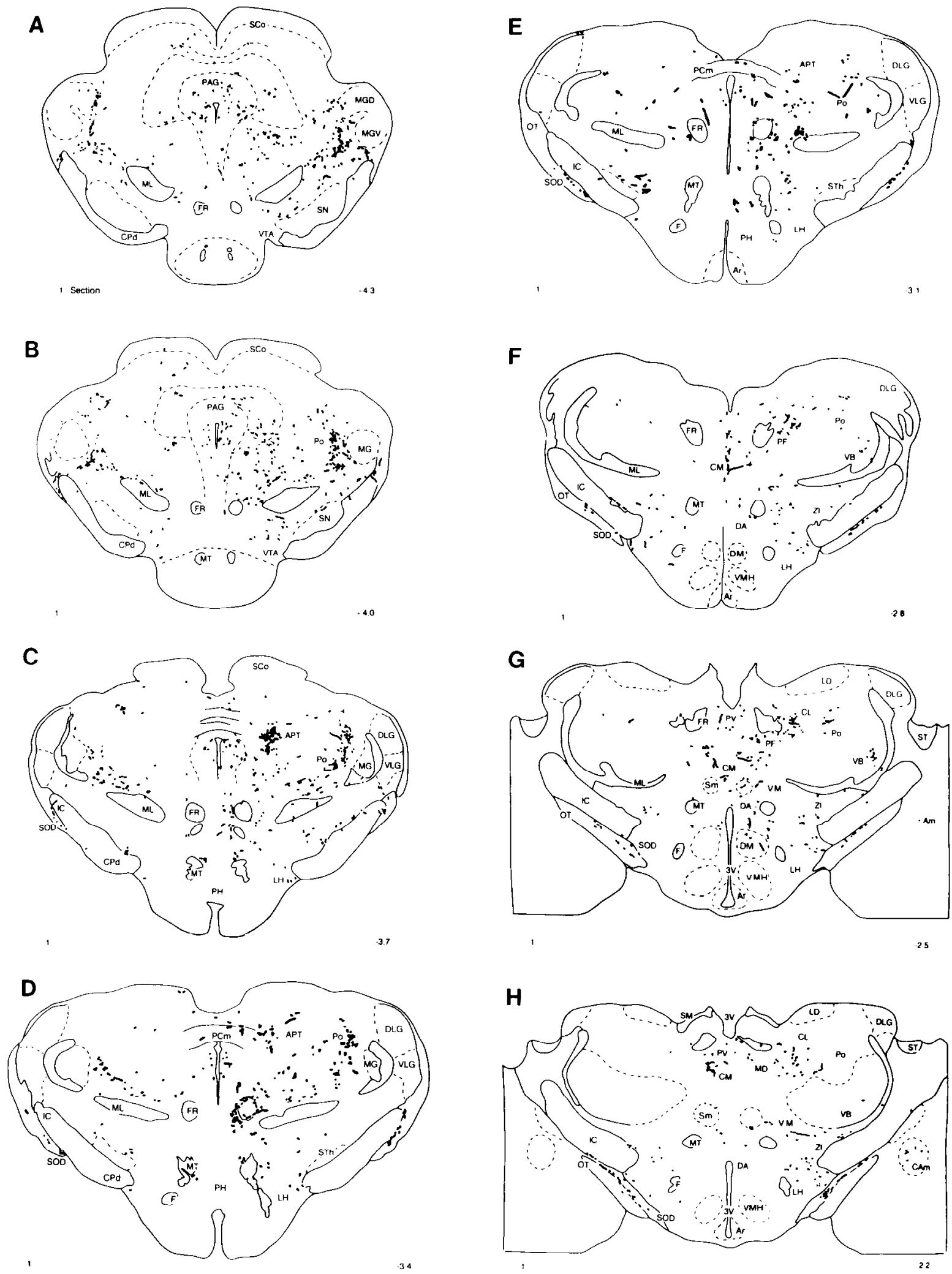

Figure 2. Locations of labeled fibers in transverse sections through the diencephalon and telencephalon (case CE-2). Each thick line represents the location and extent of a labeled axon. Solid lines represent edges of the sections or borders between gray and white matter. Thin broken lines represent other architectonic borders. The number of sections mapped onto each drawing is indicated at lower left of each. The approximate distance in $\mathrm{mm}$ rostral $(+)$ or caudal $(-)$ to the anterior commissure is indicated at lower right of each drawing. Ipsilateral, left; contralateral, right. See Appendix for abbreviations. 


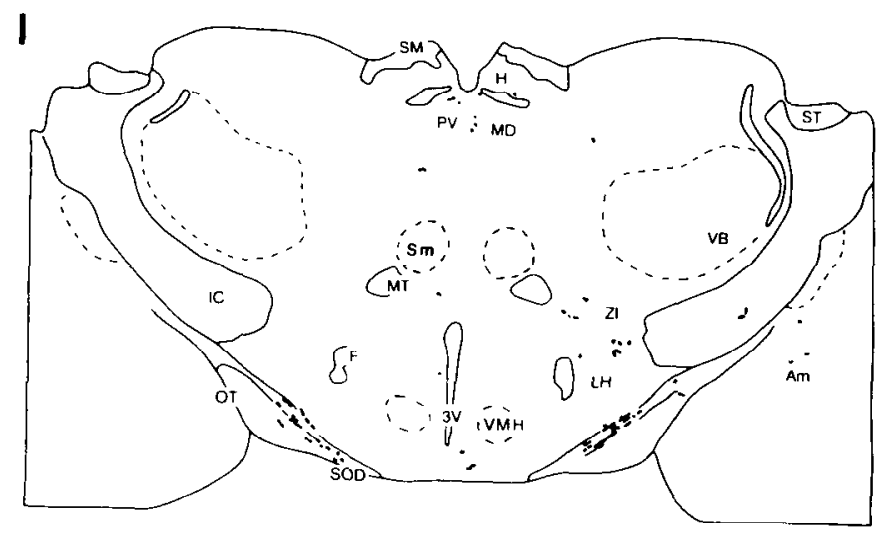

M
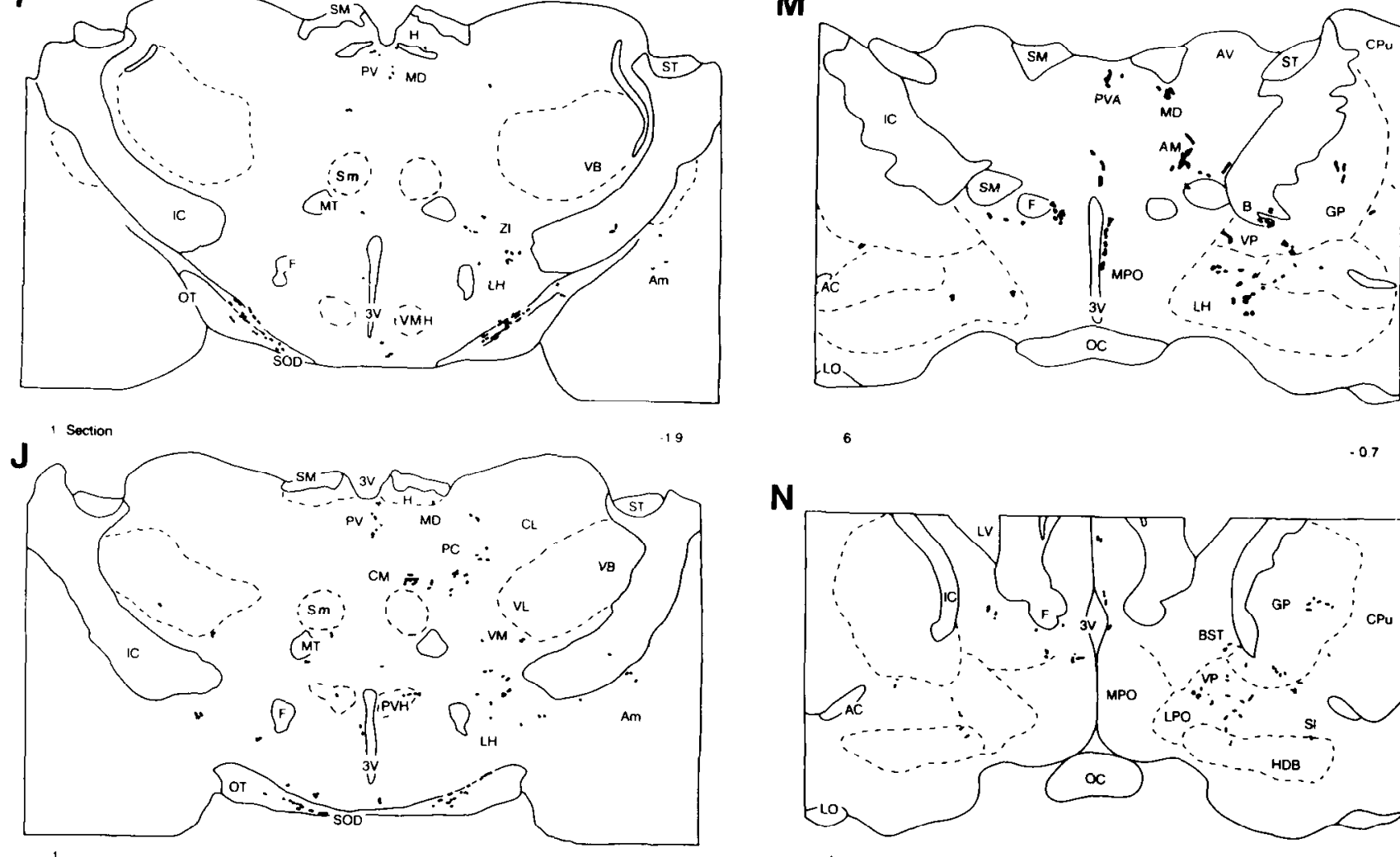

$\mathbf{N}$

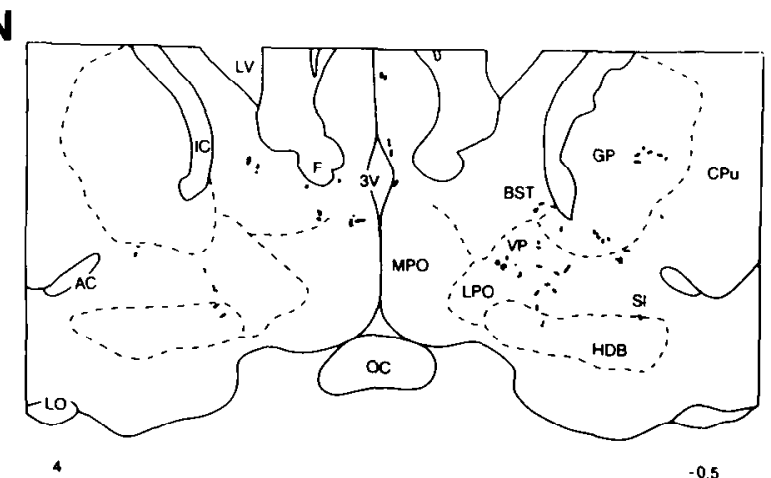

K

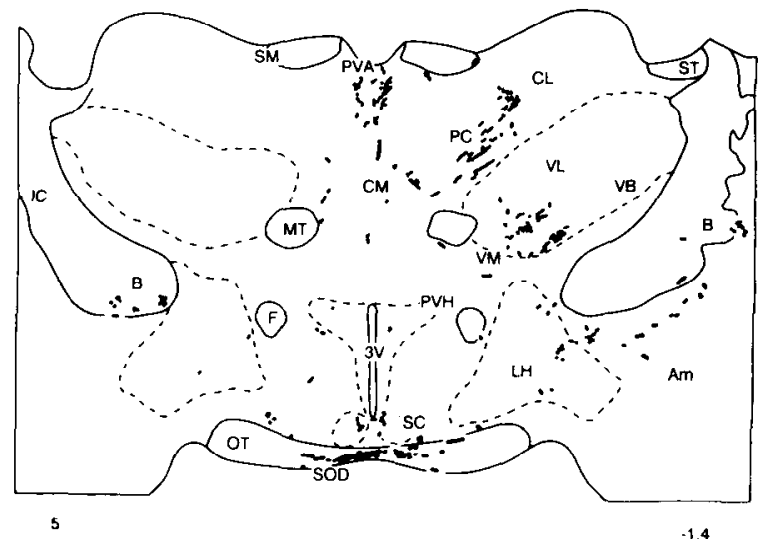

0

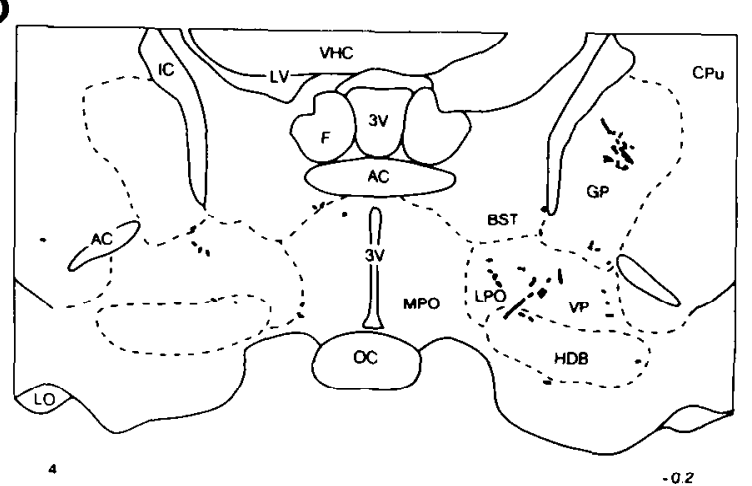

$\mathbf{L}$

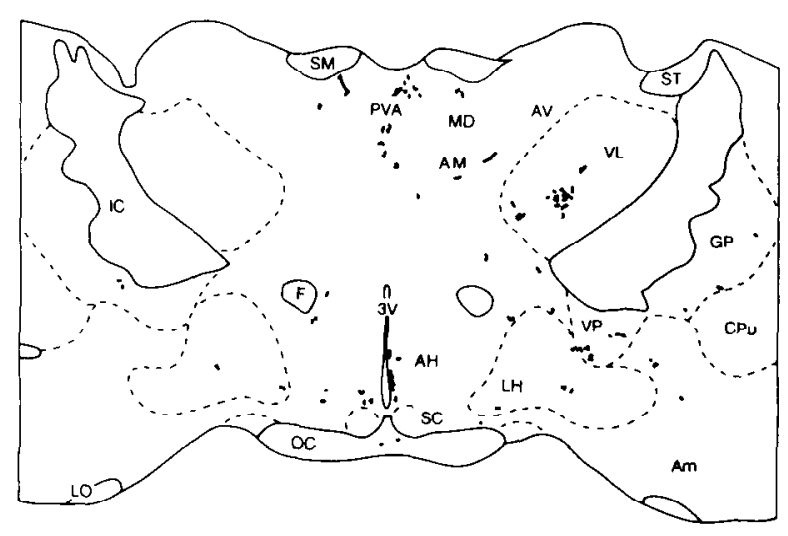

P

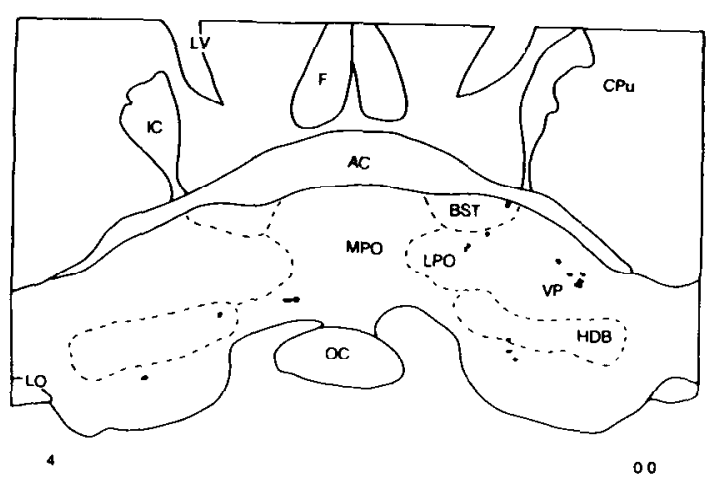

Figure 2. Continued. 
Q

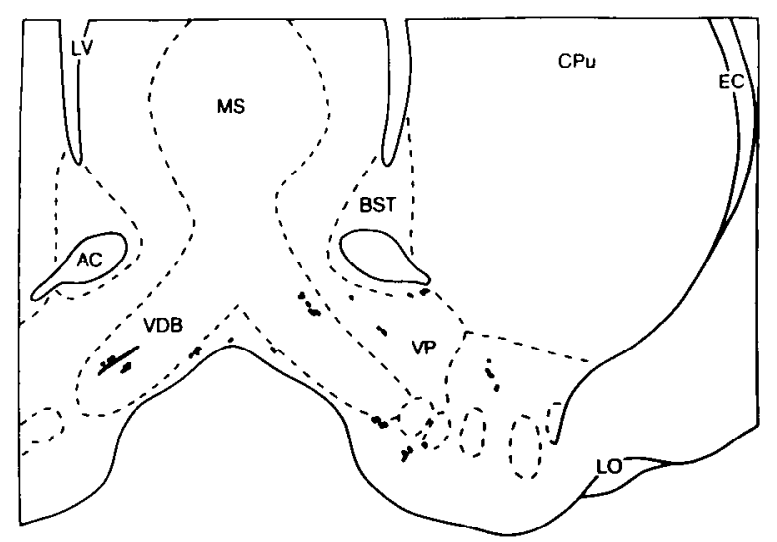

6 Sections

R

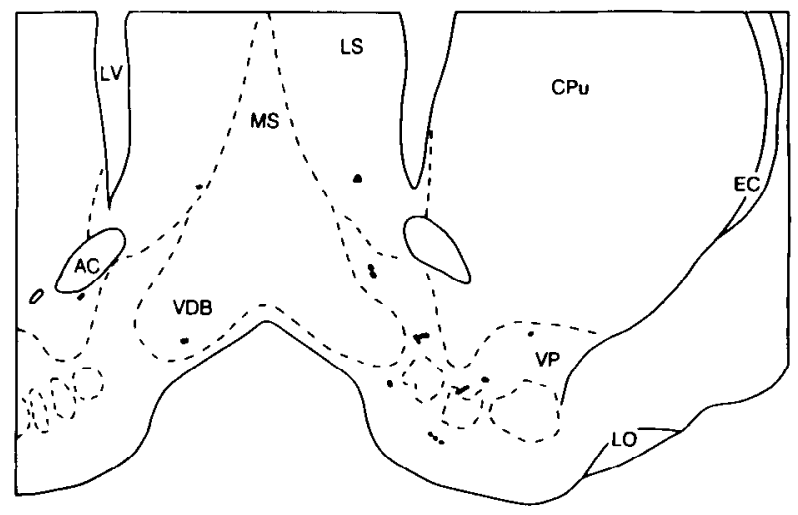

5

$+0.7$

S

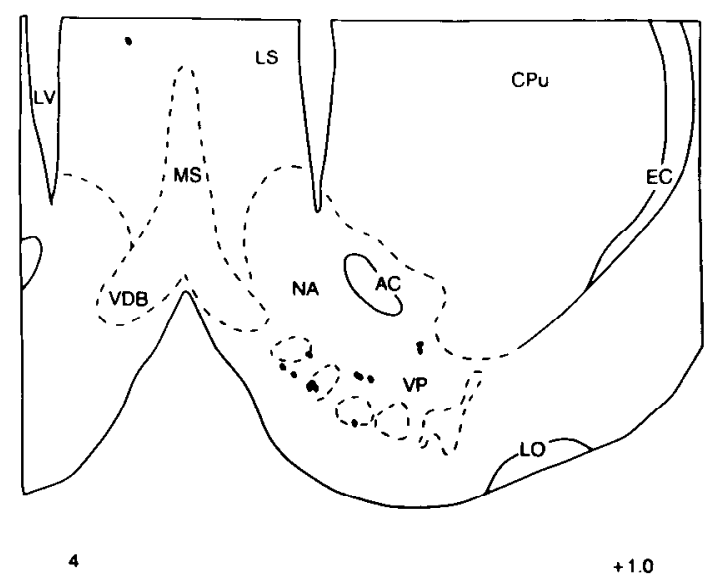

T

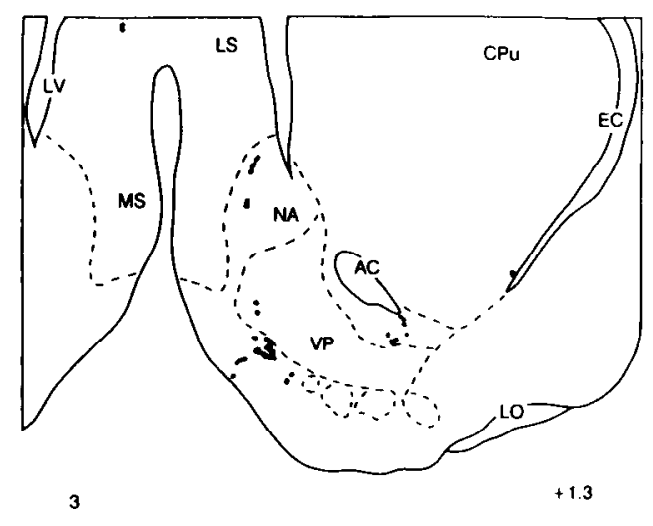

$\mathbf{U}$

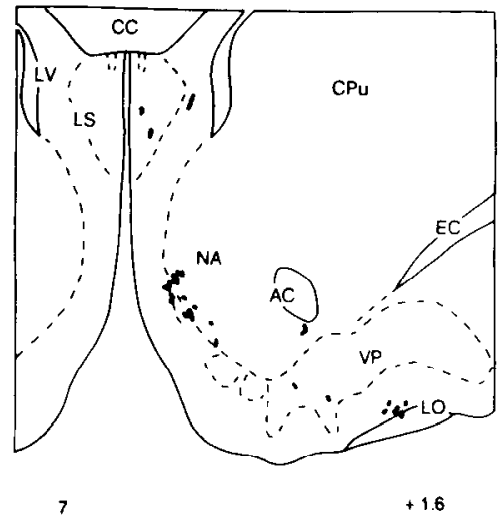

$+1.6$

\section{v}

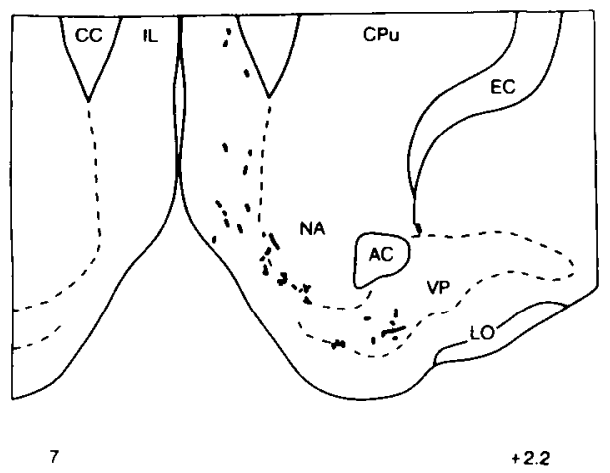

$1 \mathrm{~m} \mathrm{~m}$

Figure 2. Continued.

scattered within the lateral septum (Figs. $2 R-U, 6 B$ ). Labeled fibers were at the ventral border of the corpus callosum, about where the genu and forceps minor of that structure meet, just medial to the rostral end of the lateral ventricle (Figs. $3 \mathrm{H}, 6 \mathrm{C}$ ). These fibers appeared to be continuations of those that ran along the border between nucleus accumbens and the lateral septum. In horizontal sections of one case, fibers appeared to lead through the cingulum (Fig. $3 G, H$ ) into the medial orbital cortex (Figs. $3 I-K, 4 C$ ). Some labeled fibers were also observed slightly more laterally, in the border between the cingulum and the external capsule (Fig. $3 E, F$ ).

More laterally at rostral levels, labeled fibers were observed along the external capsule, dorsal and lateral to the anterior commissure (Figs. $2 T, V ; 6 C$ ) and alongside it (Fig. 6A,B). In 

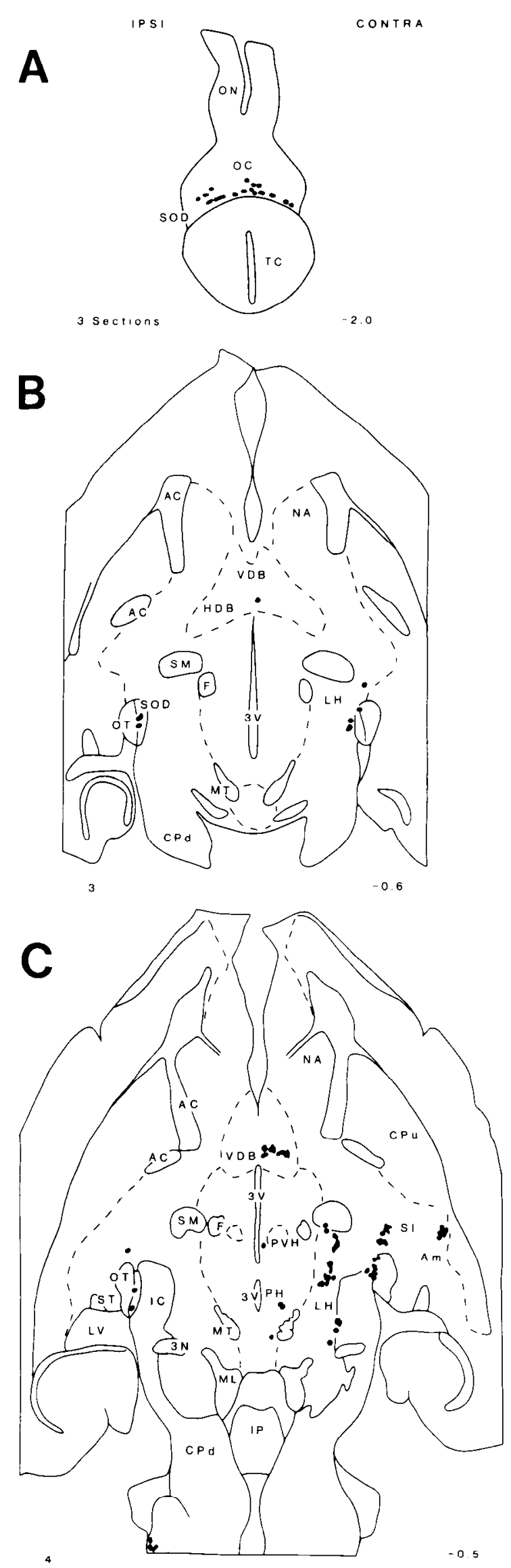
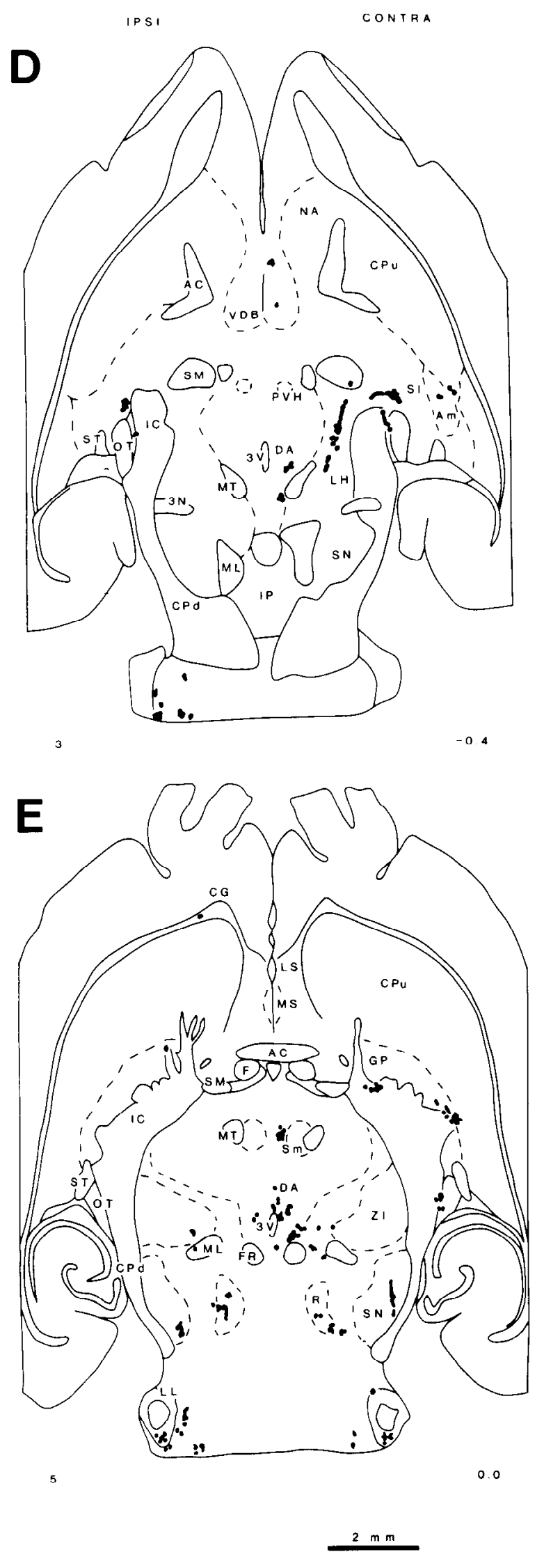

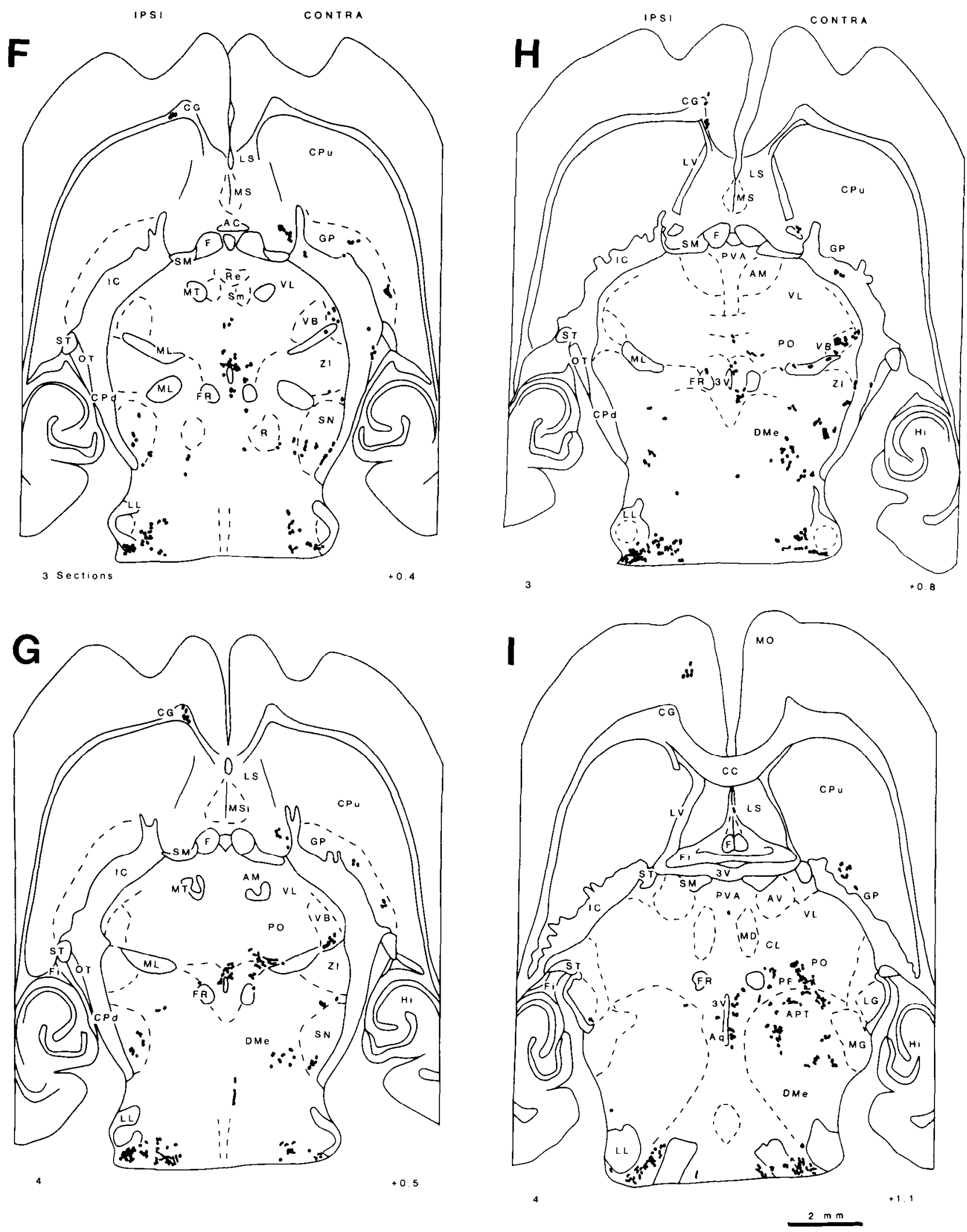

Figure 3. Locations of labeled fibers in horizontal sections through the brain (case CE-4). The numbers of sections and mapping conventions are indicated as in Figure 2. The approximate distance in $\mathrm{mm}$ dorsal $(+)$ or ventral $(-)$ to the anterior commissure is indicated at the lower right. Ipsilateral, left; contralateral, right. See Appendix for abbreviations. 

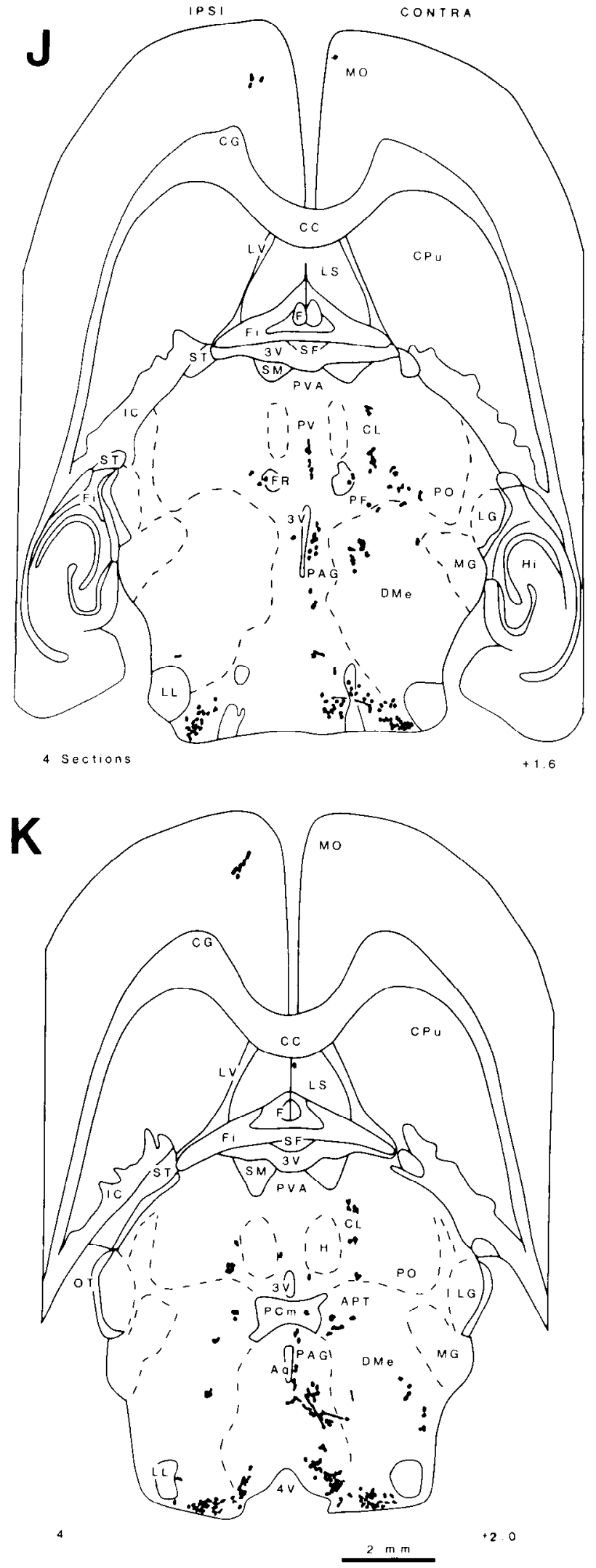

Figure 3. Continued. the most rostral transverse sections, labeled fibers were seen just dorsal to the anterior commissure, both within the nucleus accumbens (not shown) and lateral to it, in the cortex ventrally adjacent to the claustrum (Fig. 7).

\section{Discussion}

Previous anterograde evidence of spinohypothalamic fibers In spite of many anatomical studies of projections from the spinal cord to the brain (for references, see Burstein et al., 1987, 1990a), there has not been general recognition of spinal projections to the hypothalamus or telencephalon prior to our current series of studies (Burstein et al., 1987, 1990a; Burstein and Giesler, 1989). However, cells in the medullary dorsal horn, considered analogous to the spinal cord dorsal horn, have been reported to project to the basal ganglia (Yasui et al., 1987). This is the only previous report of which we are aware of projections analogous to spinotelencephalic projections. Other reports have indicated spinohypothalamic projections.

Some of these reports concerned fibers of spinal origin in the supraoptic decussation at the lateral and ventral extents of the hypothalamus. Minderhoud (1967) and Lund and Webster (1967) observed degeneration of crossing fibers in the ventral component of the supraoptic decussation in rats after lesions of the spinal cord at high thoracic or high cervical levels, respectively. Chang and Ruch (1949) found degenerating axons in the supraoptic decussation of monkeys following spinal lesions. Minderhoud (1967) noted that fibers of the supraoptic decussation, not necessarily of spinal origin, terminate in many of the areas in which we observed labeled fibers: near the optic tract in the lateral part of the hypothalamus, in the medial part of the globus pallidus and substantia innominata, and in the dorsolateral part of the subthalamus, ventral to the lateral geniculate body (only in this subthalamic region did he specifically include fibers of spinal origin).

Some previous reports of anterograde tract tracing in various species have indicated spinal projections to other areas within the hypothalamus in which we observed labeling. Degeneration has been reported in the lateral hypothalamus of hedgehogs (Ring and Granchow, 1983) and cats (Anderson and Berry, 1959) and in the posterior hypothalamus of rats, cats, and rabbits (Yamada and Otani, 1978) following spinal lesions. Craig (1988) has recently reported anterograde labeling with PHA-L in the dorsal hypothalamus of cats after spinal injections. Kerr (1975) reported terminal degeneration in the medial hypothalamus of monkeys following lesions of the ventral funiculus of the spinal cord. After injections of HRP into the spinal cord of rabbits, Ju (1984) interpreted labeling of fibers in the hypothalamus as being due to HRP transported from cell bodies at the spinal injection site. Craig and Burton (1985), however, noted that the presence of large numbers of neurons retrogradely labeled with HRP in the brain confounded the interpretation of labeled fibers in the hypothalamus after spinal injections in cats or raccoons.

\section{Technical considerations}

The previous lack of general recognition of spinohypothalamic and spinotelencephalic pathways was probably due at least partly to technical constraints. HRP and its conjugated forms have the disadvantage mentioned above of being transported retrogradely as well as anterogradely, confounding interpretation of labeled fibers. Degeneration allows study of a large portion of an ascending pathway following a relatively rostral lesion disrupting the pathway, but can depend for success on careful se- 

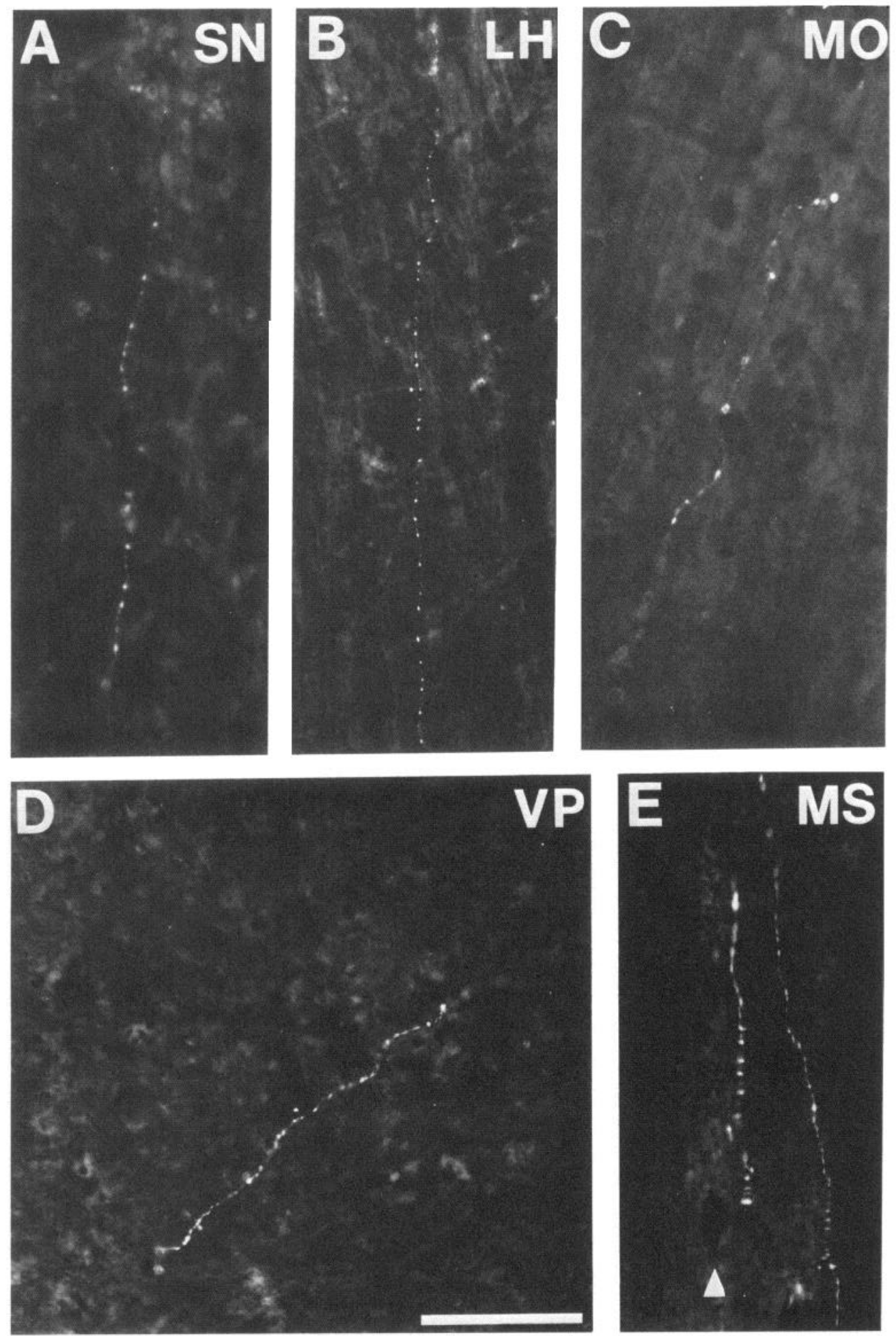

Figure 4. Photomicrographs of labeled fibers, ipsilateral (i) or contralateral (c) to the injections. $A$, Substantia nigra (c); $B$, medial forebrain bundle in lateral hypothalamus (c); $C$, medial orbital cortex (i); $D$, ventral pallidum (c); $E$, medial septum (c; midline indicated by arrowhead). $A-C$ are horizontal sections, rostral up, from case CE-4; $D, E$ are transverse sections from cases $\mathrm{CE}$ 2 and CE-1, respectively. Scale bar: 50 $\mu \mathrm{m}, A, C ; 100 \mu \mathrm{m}, B, D, E$. lection of survival times, especially for small fibers (de Olmos et al., 1981). Autoradiographic techniques rely on a substantial density of label for detection above background, and the amino acids used are not readily taken up by fibers of passage, resulting in difficulty labeling a large portion of the projection at once. PHA-L injected iontophoretically has this disadvantage (for this type of study) of low affinity for fibers of passage (Gerfen and Sawchenko, 1984; Cliffer and Giesler, 1988). However, in con- trast to the other techniques, the ability to detect detailed morphology allows unequivocal identification of individual PHA-Llabeled fibers that are sparsely distributed and of very small caliber, as were many of the labeled fibers we observed in hypothalamic and telencephalic areas.

A potential problem for interpreting the results of our experiments would be created by anterograde labeling of axons of cells remote from the injection sites. Potential problematic 


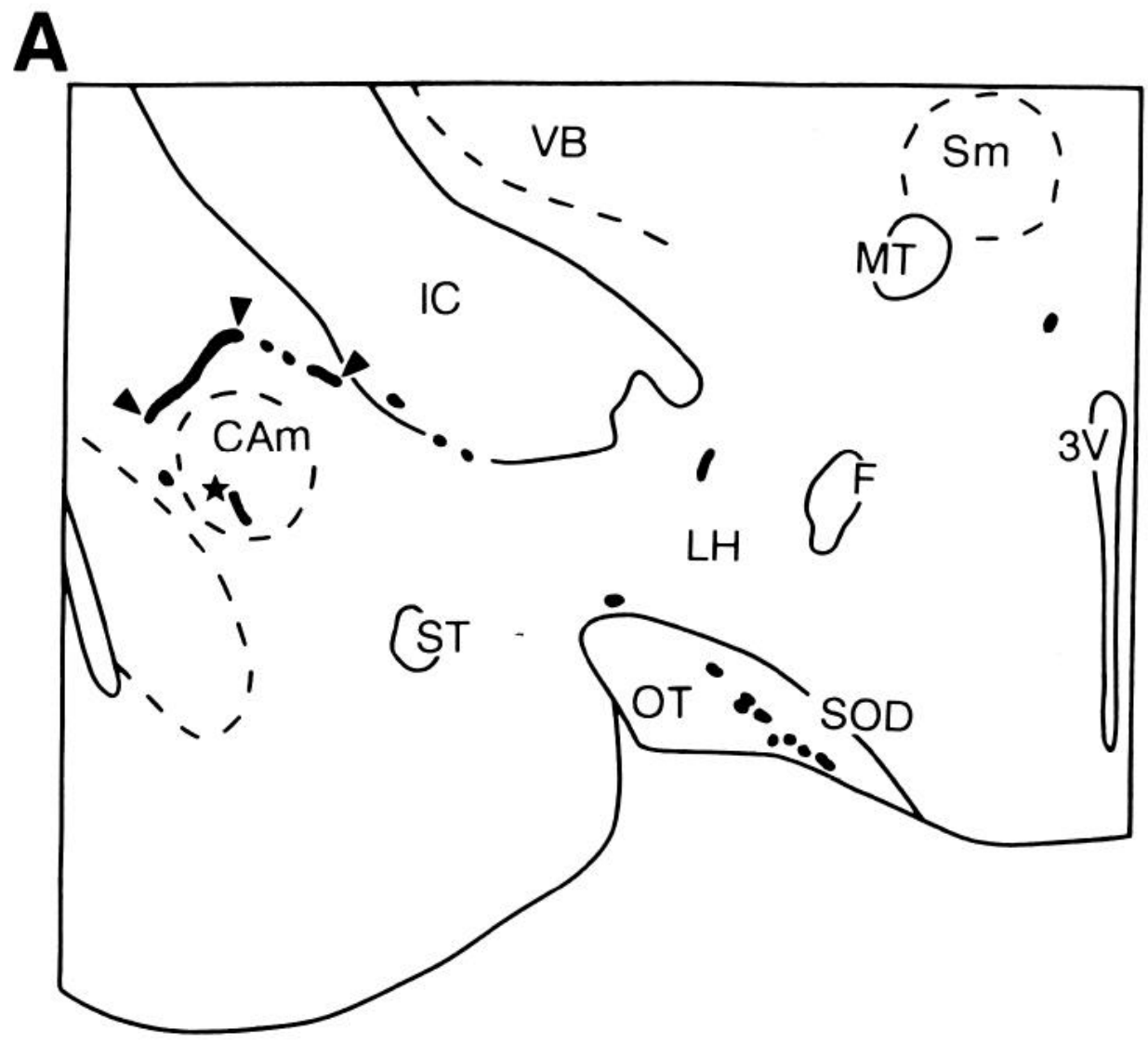

Figure 5. Labeled fiber leading into the amygdala, ipsilateral to the injection, from case CE-1. A, Drawing showing locations of the labeled fibers shown in $B$ and $C$, with correspondence indicated by symbols. Mapping conventions are the same as in Figure 2. B, Photomicrograph of a long segment of labeled fiber. $C$, Photomicrograph of a fiber in the central nucleus of the amygdala. Scale bar: $0.7 \mathrm{~mm}, A ; 120 \mu \mathrm{m}, B$ ; $60 \mu \mathrm{m}, C$. See Appendix for abbreviations.

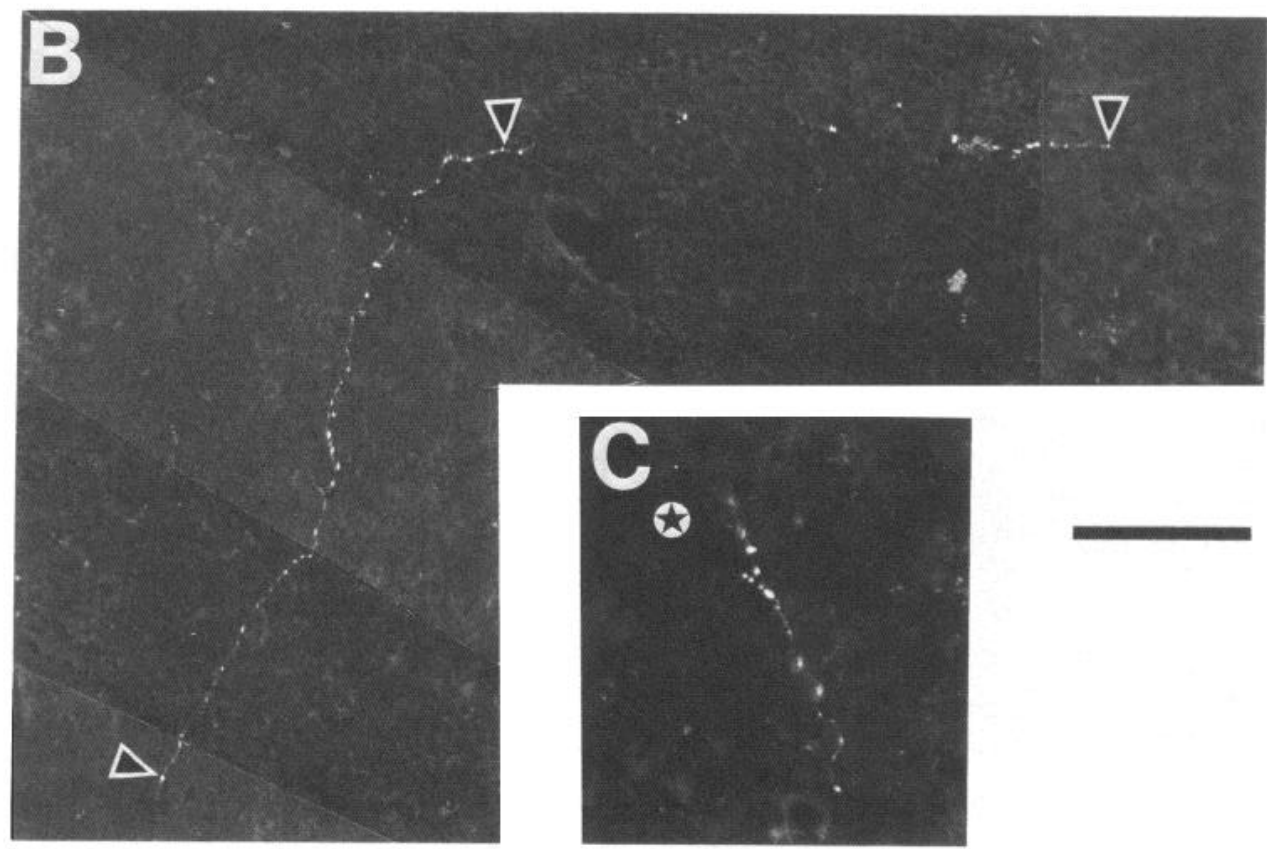

sources of such labeling are transsynaptic labeling and retrograde labeling with subsequent anterograde transport in collateral axons. We do not believe that either of these processes contributed importantly to confound the interpretation of the labeling we observed. Anterograde labeling through axons of passage was not of concern because such labeling would be in fibers of cells situated more caudally, but still in the spinal cord.
Transsynaptic labeling is unlikely with PHA-L. In a large number of studies, anterograde PHA-L labeling, often dense, has been observed with the electron microscope, with no indication of labeling in elements postsynaptic to labeled terminals (e.g., Keller et al., 1985; Wouterlood and Groenewegen, 1985; Kita and Kitai, 1987; Cucchiaro et al., 1988; Smith and Bolam, 1989). In addition, in many sections, including those 
A

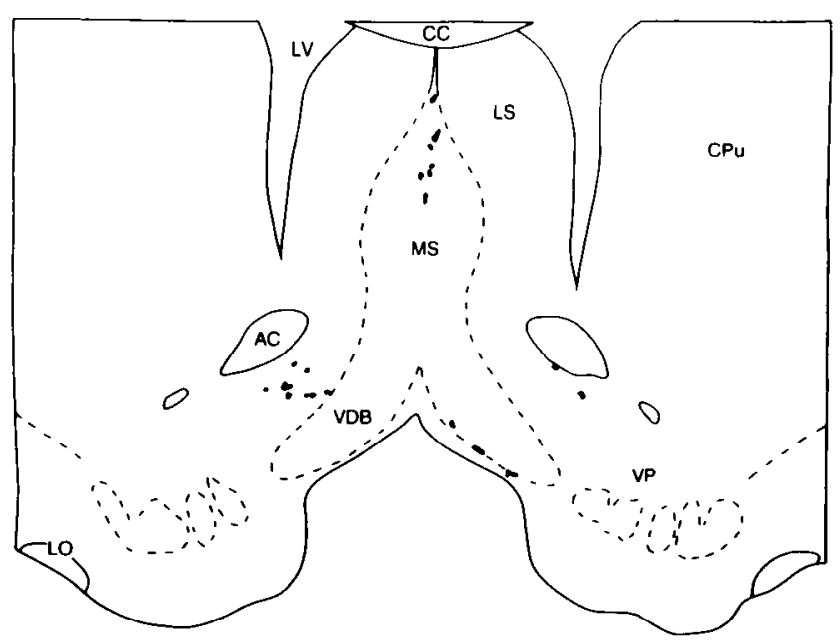

4 Soctions

B

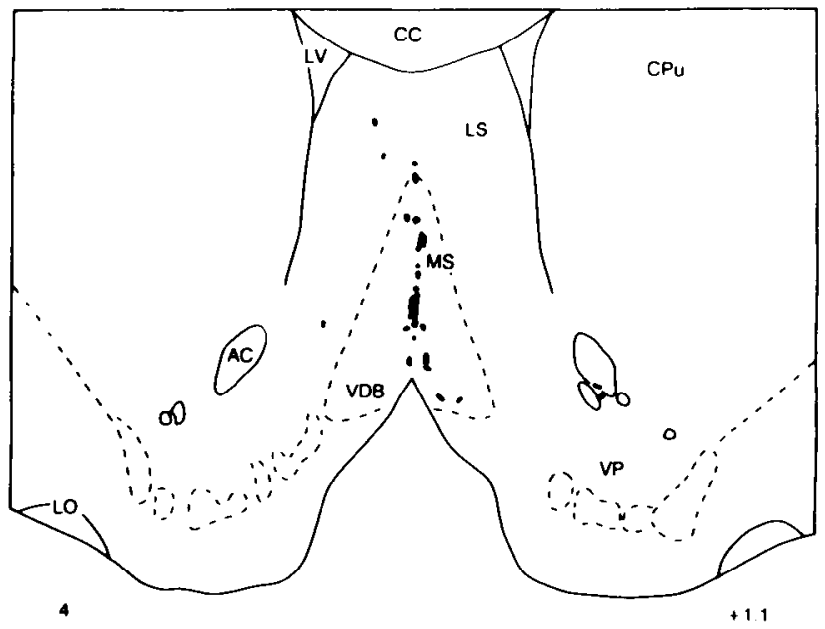

C

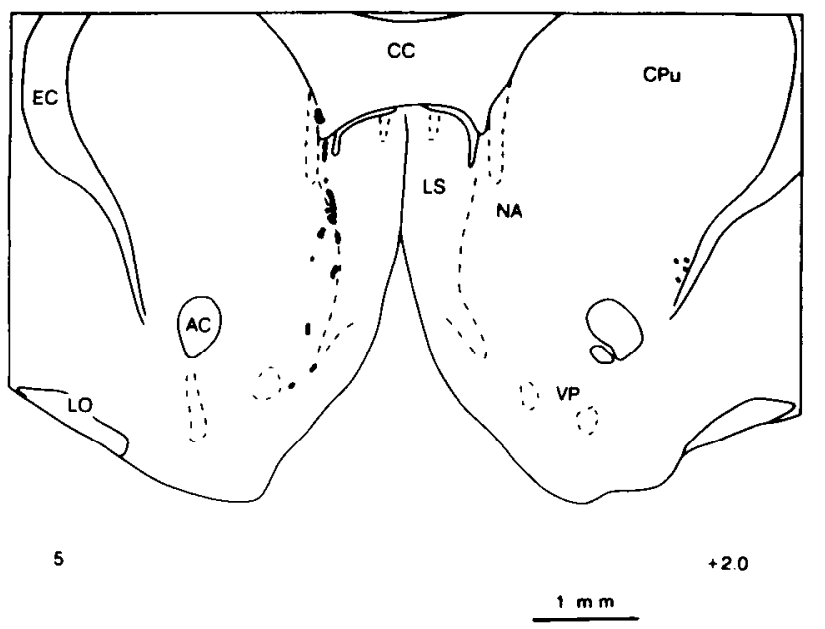

Figure 6. Locations in transverse sections of labeled fibers at rostral parts of the brain from case CE-1. Ipsilateral, left; contralateral, right. The numbers of sections are indicated as in Figure 2, and mapping conventions are also the same. The approximate distance in $\mathrm{mm}$ rostral to the anterior commissure is indicated at lower right of each drawing. See Appendix for abbreviations.

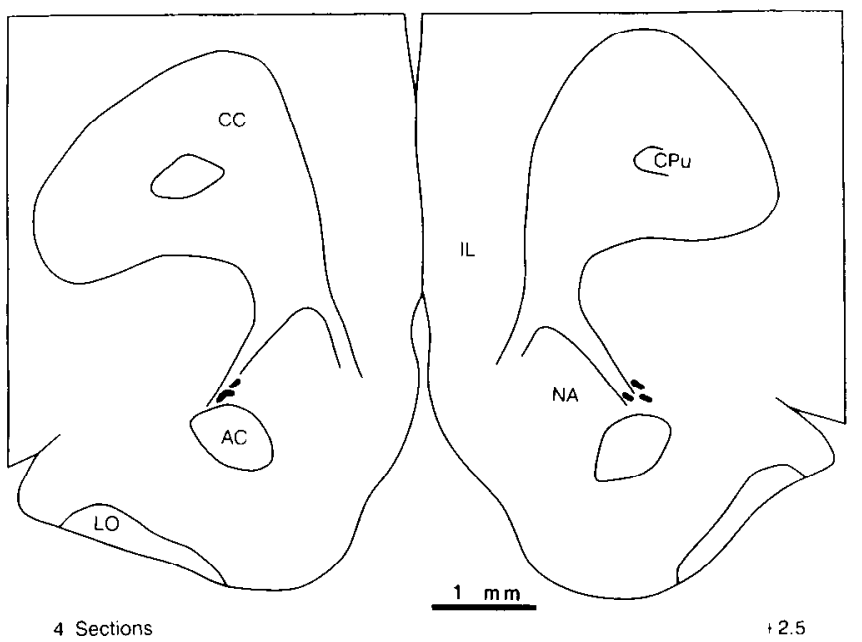

Figure 7. Composite map of labeled fibers at the most rostral part of the brain analyzed in transverse sections from cases CE-1, CE-2, and CE-3. Ipsilateral, left; contralateral, right. The level, as indicated, is about $2.5 \mathrm{~mm}$ rostral to the anterior commissure. The number of sections is indicated as in Figure 2, and mapping conventions are also the same. See Appendix for abbreviations.

with heavy anterograde labeling in the dorsal column nuclei, we never detected a labeled cell body remote from the injection (Cliffer and Giesler, 1989). In contrast to these observations for PHA-L, other lectins (unconjugated or conjugated) that are transneuronally transported label cell bodies in terminal fields of labeled axons (Fabian and Coulter, 1985; Peschanski and Ralston, 1985).

Although retrograde labeling with PHA-L has been noted under some conditions (Gerfen and Sawchenko, 1984; Lee et al., 1988; Shu and Peterson, 1988), the only labeled cell bodies we have observed after injections in the spinal cord have been in the vicinity of the injections (Cliffer and Giesler, 1989). We did not observe labeled cell bodies anywhere in the brain in the present study.

We cannot definitively rule out the possibility that labeling occurred transsynaptically or through collaterals without labeling cell bodies, but we consider such labeling unlikely. Nevertheless, spinal projections to areas in which we observed labeled fibers must be confirmed. Retrograde labeling has confirmed projections from the spinal cord to the hypothalamus (rats: Burstein et al., 1987, 1990a; Carstens et al., 1990; cats: Katter et al., 1991) and to the septum and nucleus accumbens (Burstein and Giesler, 1989). The spinal origin of fibers in the hypothalamus and crossing in the supraoptic decussation has been confirmed by antidromic activation (Burstein et al., 1987). As noted above, previous reports using anterograde tracing indicated that fibers in the hypothalamus originate in the spinal cord.

Fibers labeled in the diencephalon and telencephalon after spinal injections of PHA-L were sparser and more variable in density than in the dorsal column nuclei (cf. Cliffer and Giesler, 1989). The consistently high density of labeled fibers in the postsynaptic dorsal column pathway may be due to the great number of cells projecting in that pathway (E. Ranheim, C. Andersen, and G. J. Giesler, Jr., unpublished observations), even compared to the number in the spinothalamic tract (Lima and Coimbra, 1988; Burstein et al., 1990c), but might also reflect a greater tendency of PHA-L to be taken up by some cells than by others. 
In the diencephalon and telencephalon, variability in presence or density of labeled fibers in given areas could conceivably reflect differences in the projections among individual animals, but is probably caused more by technical factors. As a result, the density of labeled fibers in a particular area may not definitively indicate the density of the spinal projection to that area. The portion of the spinal cord we could inject iontophoretically was relatively restricted. The presence and densities of labeled fibers in a given area probably depend on particular locations of the injections in the gray matter. Pressure injections could have been more extensive; PHA-L has been used with pressure injections (Casale et al., 1988), but in several attempts, we were unable to obtain labeling as extensive or as bright as that from iontophoretic injections (K. D. Cliffer and G. J. Giesler, Jr., unpublished observations).

In spite of the variability, our positive results were consistent both with previous reports of spinal projections to the thalamus and midbrain and, for areas to which projections had not been previously reported, among the cases we analyzed. We refer to labeled fibers as indicating "projections"; varicosities in the areas in which we report labeling indicated functional associations. However, definitive proof of functional associations in an area cannot be obtained from a light microscopic study.

\section{Comparison of labeling in thalamus to previous results}

The locations of labcled fibcrs in the thalamus generally corresponded to those that have been observed in previous studies of the spinothalamic tract. The most extensive agreement is with the studies of Craig and Burton (1985) in cats and raccoons. Projections to the ventrobasal complex, to the posterior complex, and to the central lateral nucleus have been consistently observed (reviewed in Mehler, 1969; Willis, 1985, 1986). Projections to intralaminar nuclei other than the central lateral nucleus, to the midline nuclei, and to the mediodorsal nucleus and the habenula have been less commonly observed, and the validity of some of these has been questioned on technical grounds (Peschanski and Ralston, 1985). PHA-L appears to be free of the postulated confounding factors of transneuronal labeling or labeling of collaterals; thus, our observations add evidence for these projections.

Mehler (1969) observed that the degeneration in the ventrobasal complex of rats after spinal lesions was relatively rostral compared to that in other species. He interpreted degeneration in the caudal ventrobasal thalamus as being solely of fibers passing to more rostral levels. On this basis, he argued for the term "ventrobasal complex" (VB) to refer to the projection area, rather than "nucleus ventralis posterior lateralis (VPL)," which would imply a strict homology to the more caudal projection area in primates. This interpretation of primarily rostral terminal labeling was similar to that of Lund and Webster (1967), Zemlan et al. (1978), and Faull and Mehler (1985). McAllister and Wells (1981) and Peschanski et al. (1983) did find evidence for spinal projections to the caudal part of VB. The present results with $\mathrm{PHA}-\mathrm{L}$ also indicate a projection to the caudal part of VB from the cervical and lumbar enlargements, indicating an area that could indeed be homologous to the caudal part of VPL (VPLc, Olszewski, 1952) in primates. Our results provide evidence against the hypothesis (Lund and Webster, 1967) that the caudal part of $\mathrm{VB}$ receives afferents only from the most rostral cervical segments.

Another area of labeled fibers in the thalamus, more rostral, in the border region between the ventrolateral thalamic nucleus (VL) and VB, appears to correspond both to the rostral area of terminations observed by Mehler (1969) and to VPLo (oral part of VPL; Olszewski, 1952) in primates. Somatotopy in this projection is suggested by the more lateral and dorsal location of labeled fibers after a thoracic injection than after a cervical injection. In addition, a distinct concentration of labeled fibers within VL was evident in our results. Labeling indicating spinal projections to VL and/or a VL/VPL border area has been observed in cats (Jones and Burton, 1974; Burton and Craig, 1983; Craig and Burton, 1985), raccoons (Burton and Craig, 1983; Craig and Burton, 1985), and monkeys (Boivie, 1979).

The lack of many labeled fibers in nucleus submedius was consistent with recent findings that few cells in the spinal cord are labeled after injections of the sensitive retrograde tracers fluoro-gold and fast blue into that nucleus in the rat (Dado and Giesler, 1990).

\section{Courses of the labeled fibers}

Some of the pathways through which the labeled fibers projected can be inferred by their locations from section to section. From the area of the spinothalamic tract contralateral to the injection, a group of axons appeared to course to the posterior and ventrobasal thalamus. This route is well known (e.g., Mehler, 1969). Another group of fibers appeared to course from the spinothalamic tract laterally around the rostral/dorsal end of the internal capsule to enter the supraoptic decussation adjacent to the optic tract. Many labeled fibers clearly crossed the midline in the supraoptic decussation, and at least some appeared to continue back again caudally on the opposite side (now ipsilateral to the injection), in the course described by Minderhoud (1967) for fibers in this structure. We have followed the axons of such fibers by antidromically activating the cell bodies in the spinal cord with small currents from successive points along their axons in the supraoptic decussation and crossing the midline ( $R$. Burstein, R. J. Dado, K. D. Cliffer, and G. J. Giesler, Jr., unpublished observations). Latencies increased (indicating increasing distances from the cell body) from the side contralateral to the recorded cell to the side ipsilateral to it. Thus, such fibers cross the midline twice, once in the spinal cord, presumably near their origin, and again in the supraoptic decussation. Some labeled fibers appeared to enter the hypothalamus from the supraoptic decussation, either to the lateral hypothalamus as they cmcrged from their course between the optic tract and the internal capsule, or to the ventral part of the medial hypothalamus, from the ventrally adjacent supraoptic decussation. Some of the fibers entering the supraoptic decussation from the area of the spinothalamic tract may be collaterals of spinothalamic tract cells that also project to the hypothalamus via the supraoptic decussation. Such collaterals were suggested by our activation of some cells in the spinal cord antidromically both from the ventrobasal thalamus and from the hypothalamus (Burstein, Dado, Cliffer, and Giesler, unpublished observations).

Other labeled fibers appeared to enter the diencephalon by a second route, from the midbrain tegmentum medial to the distinct, more lateral part of the spinothalamic tract; this second route leads to the intralaminar thalamic nuclei (Mehler, 1969). Fibers in the more ventral part of the midbrain tegmentum appeared to continue rostrally to the hypothalamus via a parallel route.

The observation of labeled fibers running along with the medial forebrain bundle suggests that this is a route by which fibers of spinal origin reach the lateral preoptic area and telencephalic areas. Some labeled fibers appeared to run from the region near the optic tract laterally to the amygdala or rostrally, laterally, 
and dorsally to the nucleus basalis and globus pallidus (Fig. 2). These appeared to have diverged from the area of the fibers leaving the spinothalamic tract and running towards the supraoptic decussation. Ipsilateral to the injection, they may project to the amygdala via the supraoptic decussation (Fig. 5).

\section{Sensation, including nociception}

Our physiological studies (Burstein et al., 1987) showed that nearly all cells in the lumbar enlargement of the spinal cord that could be demonstrated to project to the medial or lateral hypothalamus and that had cutaneous receptive fields exhibited nociceptive properties. Cells in the hypothalamus have been demonstrated to respond to a variety of somatosensory (including visceral) stimuli (for references, see Burstein et al., 1987, 1990a). Many other areas in which we observed labeled fibers after injections in the spinal cord have also been shown to be involved in processing of somatosensory information.

Involvement of thalamic areas in somatosensation, including nociception, has been reviewed by Albe-Fessard et al. (1985), Willis (1985, 1986), and Fields (1987). The involvement of VB in nociception is well established (e.g., Kenshalo et al., 1980). Nociceptive responses have also been recorded in the posterior thalamus, in the intralaminar and adjacent medial thalamic nuclei (reviewed by Albe-Fessard et al., 1985; Willis, 1985, 1986; see also Palestini et al., 1987; Dostrovsky and Guilbaud, 1988, 1990; Miletic and Coffield, 1989), and in the habenula (Benabid and Jeaugey, 1989).

Bullitt (1990) has recently shown that cells in many of the areas in which we found labeled fibers increase in immunoreactivity to an antibody to Fos protein upon noxious stimulation of the periphery. $C$-fos is a proto-oncogene that shows increased expression in some activated cells (e.g., Hunt et al., 1987; Morgan et al., 1987). Following noxious, but not nonnoxious, stimulation, increased numbers of cells showed immunoreactivity for the protein in the following areas that contained labeled fibers in the present study: (1) in the thalamus: midline nuclei, intralaminar nuclei, VB, posterior complex, and zona incerta; (2) in the hypothalamus: lateral hypothalamus, posterior hypothalamus, dorsal hypothalamic area, and paraventricular hypothalamic nuclei; and (3) in the telencephalon: amygdala. Direct spinal input may contribute to changes in these areas in response to noxious stimulation. Determination of whether noxious peripheral stimulation results in increases in $c$-fos-like immunoreactivity in other telencephalic areas and in more rostral diencephalic areas that were not analyzed in Bullitt's (1990) study would be interesting.

Orbitofrontal cortex has been implicated in motivational/ affective aspects of pain. Surgical removal of parts of orbitofrontal cortex has been observed to amcliorate affective responses to severe chronic pain (White and Sweet, 1969). Medial thalamic areas, including nucleus submedius, project to orbitofrontal cortex (Krettek and Price, 1977) and have been hypothesized as a route by which spinal and trigeminal nociceptive information reaches orbitofrontal cortex (Craig et al., 1982). Our results in the present study indicate that fibers of spinal origin project directly to orbital cortex and infralimbic cortex, providing an alternative, direct pathway by which somatosensory, possibly nociceptive, information can reach that region of the brain.

Potential reciprocal innervation, antinociception, and autonomic function

The projection of fibers originating in the spinal cord to areas of the brain that themselves contain cells that project to the spinal cord suggests the possibility of reciprocal circuits. In the hypothalamus, cells in the following areas in which we observed labeled fibers project to the spinal cord: lateral hypothalamic area, posterior hypothalamic area, dorsal hypothalamic area, paraventricular nucleus, retrochiasmatic area, and medial and lateral preoptic areas (reviewed in Holstege, 1987; Hosoya et al., 1987; Swanson, 1987; Cechetto and Saper, 1988). Cells in the amygdala also project to the spinal cord (Mizuno et al., 1985; Sandrew et al., 1986; Follett, 1989) and might participate in reciprocal interactions with spinoamygdala cells.

Hypothalamic cells project throughout the length of the spinal cord and widely in the gray matter, including the intermediolateral cell column and the substantia gelatinosa (reviewed in Swanson, 1987). Reciprocal connections between the hypothalamus and the dorsal horn in cervical and lumbar cord could be involved in sensory feedback processes involving spinohypothalamic cells, including antinociception. Stimulation in either medial (e.g., Duysens et al., 1989) or lateral (e.g., Aimone et al., 1988; Behbehani et al., 1988) hypothalamus, including the medial or lateral preoptic areas (Carstens et al., 1982; Lim et al., 1985; Shyu and Lin, 1985; Mokha et al., 1987) can have antinociceptive effects.

Stimulation in many of the other areas with labeled fibers can also have antinociceptive effects that might normally be elicited or regulated with involvement of direct spinal input. These areas include intralaminar thalamic nuclei (Andy, 1983), the habenula (Cohen and Melzack, 1985; Mahieux and Benabid, 1987), the septum (Carstens et al., 1982), and nucleus accumbens (e.g., Yu and Han, 1989).

The projection of the paraventricular nucleus caudally as far as the sacral spinal cord (Schwanzel-Fukuda et al., 1984) raises the interesting possibility of reciprocal connections between the paraventricular nucleus and the cells in the sacral parasympathetic nucleus that project to the medial hypothalamus (Burstein et al., 1990a,b). In addition, hypothalamic involvement in autonomic processes appears to be mediated partially through descending projections from the hypothalamus to the intermediolateral cell column of the thoracolumbar spinal cord (reviewed in Swanson, 1987). Autonomic responses might be influenced or elicited by sensory input, including nociceptive input, through fibers ascending from any level of the spinal cord to the hypothalamus. Thus, both the afferent and the efferent limbs of such processes could include direct connections between the spinal cord and the hypothalamus.

\section{Basal forebrain and limbic associations}

Functionally, the basal ganglia, including globus pallidus and substantia nigra, appear to play a role in somatosensory processing related to motor function (reviewed by Lidsky et al., 1985). These areas can be considered part of a striatopallidal system that also includes the ventral pallidum and part of nucleus accumbens (Alheid and Heimer, 1988). Thus, direct afferent fibers from the spinal cord may play a role in providing somatosensory input to these areas related to a role in motor function. The mediodorsal thalamic nucleus and intralaminar thalamic nuclei, which also receive spinal afferent input, have connections with the striatopallidal system (reviewed in Heimer et al., 1985; Zahm et al., 1987). Our observation of a spinal projection to substantia nigra is, to our knowledge, the first reported evidence of such a projection.

Somatosensory, including nociceptive, responses have been reported in cells in the amygdala (Miyagawa et al., 1986). Such information was previously indicated to reach the amygdala 
through a relay in the lateral parabrachial area (Bernard et al., 1989). The present results indicate the potential for such information to reach the amygdala directly, as well. Other telencephalic areas that contained labeled fibers can be considered to be associated with the amygdala, in the "extended amygdala" (Alheid and Heimer, 1988); these include part of the "substantia innominata," the bed nucleus of the stria terminalis, and the medial part of nucleus accumbens. This basal forebrain system has connections (reviewed by Alheid and Heimer, 1988) with other areas that receive spinal projections (present results; reviewed in Willis, 1985), including hypothalamus, zona incerta, areas in the brain-stem reticular formation, parabrachial nuclei, periaqueductal gray, and other cell groups in the medulla.

Components of the basal forebrain, including the septal complex, have been considered to be associated with the limbic system and have been implicated in motivation, emotion, attention, arousal, learning, and memory (reviewed by Alheid and Heimer, 1988; Richardson and DeLong, 1988; Everitt et al., 1989; Everitt, 1990). Somatosensory information involved in these processes might ascend to these areas at least partially through afferent fibers directly from the spinal cord. Such information could include that involved in stimulus recognition or in (positive or negative) reinforcement associated with learning trials. Evidence that nucleus basalis is involved in tactile discrimination has been presented (Wozniak et al., 1989a,b). The area of the medial septum in which we found labeled fibers contains cells that are responsive to noxious stimuli and project to the hippocampus (Dutar et al., 1985). Information ascending in direct projections from the spinal cord to the "extended amygdala" might contribute to or elicit emotional responses to painful stimuli.

\section{Conclusion}

We have demonstrated that cells in the spinal cord send axons to many hypothalamic and telencephalic areas not previously recognized as targets for such projections. Several of these projections have been confirmed with independent techniques (Burstein et al., 1987, 1990a; Carstens et al., 1990). Although others have yet to be confirmed, their apparent existence indicates interesting areas for future research on the transmission of somatosensory, including visceral sensory, information to the brain and on the nature and function of that information.

\section{Appendix}

\section{Abbreviations}

AC Anterior commissure

AH Antcrior hypothalmic arca

Am Amygdala

AM Anteromedial thalamic nucleus

APT Anterior pretectal nucleus

$\mathrm{Aq} \quad$ Aqueduct

Ar Arcuate hypothalamic nucleus

AV Anteroventral thalamic nucleus

B Basal nucleus of Meynert

BST Bed nucleus of stria terminalis

CAm Central nucleus of amygdala

CC Corpus callosum

$\mathrm{CG} \quad$ Cingulum

CL Centrolateral thalamic nucleus

$\mathrm{CM} \quad$ Central medial thalamic nucleus

CPd Cerebral peduncle

$\mathrm{CPu} \quad$ Caudate-putamen

DA Dorsal hypothalamic area

DLG Dorsal lateral geniculate nucleus

DM Dorsomedial hypothalamic nucleus

\begin{tabular}{|c|c|}
\hline DMc & Decp mesencephalic nucleus \\
\hline $\mathrm{EC}$ & External capsule \\
\hline $\mathrm{F}$ & Fornix \\
\hline $\mathrm{Fi}$ & Fimbria hippocampus \\
\hline FR & Fasciculus retroflexus \\
\hline GP & Globus pallidus \\
\hline $\mathrm{H}$ & Habenula \\
\hline $\mathrm{HDB}$ & Diagonal band of Broca, horizontal limb \\
\hline $\mathrm{Hi}$ & Hippocampus \\
\hline $\mathrm{IC}$ & Internal capsule \\
\hline IL & Infralimbic cortex \\
\hline IP & Interpeduncular nucleus \\
\hline LD & Laterodorsal thalamic nucleus \\
\hline LG & Lateral geniculate nucleus \\
\hline LII & Lateral hypothalamus \\
\hline LL & Lateral lemnicus \\
\hline LO & Lateral olfactory tract \\
\hline LPO & Lateral preoptic area \\
\hline LS & Lateral septum \\
\hline LV & Lateral ventricle \\
\hline $\mathrm{MD}$ & Mediodorsal thalamic nucleus \\
\hline MG & Medial geniculate nucleus \\
\hline MGD & Medial geniculate nucleus, dorsal \\
\hline MGV & Medial geniculate nucleus, ventral \\
\hline $\mathrm{ML}$ & Medial lemniscus \\
\hline MO & Medial orbital cortex \\
\hline MPO & Medial preoptic area \\
\hline MS & Medial septal nucleus \\
\hline MT & Mammillothalamic tract \\
\hline NA & Nucleus accumbens \\
\hline $\mathrm{OC}$ & Optic chiasm \\
\hline $\mathrm{ON}$ & Optic nerve \\
\hline OT & Optic tract \\
\hline PAG & Periaqueductal gray \\
\hline PC & Paracentral thalamic nucleus \\
\hline $\mathrm{PCm}$ & Posterior commissure \\
\hline PF & Parafascicular thalamic nucleus \\
\hline PH & Posterior hypothalamic area \\
\hline $\mathrm{Po}, \mathrm{PO}$ & Posterior thalamic nuclear group \\
\hline PV & Paraventricular thalamic nucleus \\
\hline PVA & Paraventricular thalamic nucleus, anterior \\
\hline PVH & Paraventricular hypothalamic nucleus \\
\hline $\mathrm{R}$ & Red nucleus \\
\hline $\operatorname{Re}$ & Nucleus reuniens \\
\hline $\mathrm{SC}$ & Suprachiasmatic nucleus \\
\hline SCo & Superior colliculus \\
\hline SF & Subfornical organ \\
\hline SI & Substantia innominata \\
\hline $\mathrm{Sm}$ & Nucleus submedius \\
\hline SM & Stria medullaris thalami \\
\hline SN & Substantia nigra \\
\hline SOD & Supraoptic decussation \\
\hline ST & Stria terminalis \\
\hline STh & Subthalamic nucleus \\
\hline $\mathrm{TC}$ & Tuber cinereum \\
\hline VB & Ventrobasal thalamic complex \\
\hline VDB & Diagonal band of Broca, vertical limb \\
\hline VHC & Ventral hippocampal commissure \\
\hline VL & Ventrolateral thalamic nucleus \\
\hline VLG & Ventral lateral geniculate nucleus \\
\hline VM & Ventromedial thalamic nucleus \\
\hline VMH & Ventromedial hypothalamic nucleus \\
\hline VP & Ventral pallidum \\
\hline VTA & Ventral tegmental area \\
\hline $\mathrm{ZI}$ & Zona incerta \\
\hline $3 \mathrm{~N}$ & Oculomotor nerve \\
\hline $3 \mathrm{~V}$ & Third ventricle \\
\hline $4 V$ & Fourth ventricle \\
\hline
\end{tabular}

\section{References}

Aimone LD, Bauer CA, Gebhart GF (1988) Brain-stem relays mediating stimulation-produced antinociception from the lateral hypothalamus in the rat. J Neurosci 8:2652-2663.

Albe-Fessard D, Berkley KJ, Kruger L, Ralston HJ III, Willis WD Jr 
(1985) Diencephalic mechanisms of pain sensation. Brain Res 356: 217-296.

Alheid GF, Heimer L (1988) New perspectives in basal forebrain organization of special relevance for ncuropsychiatric disorders: the striatopallidal, amygdaloid and corticopetal components of substantia innominata. Neuroscience 27:1-39.

Anderson FD, Berry CM (1959) Degeneration studies of long ascending fiber systems in the cat brain stem. J Comp Neurol 111:195-230.

Andy OJ (1983) Thalamic stimulation for chronic pain. Appl Neurophysiol 46:116-123.

Behbehani MM, Park MR, Clement ME (1988) Interactions between the lateral hypothalamus and the periaqueductal gray. J Neurosci 8 : 2780-2787.

Benabid AL, Jeaugey L (1989) Cells of the rat lateral habenula respond to high-threshold somatosensory inputs. Neurosci Lett 96:289-294.

Bernard JF, Peschanski M, Besson JM (1989) A possible spino (trigemino)-ponto-amygdaloid pathway for pain. Neurosci Lett 100:8388.

Berod A, Hartman BK, Pujol JF (1981) Importance of fixation in immunohistochemistry: use of formaldehyde at variable $\mathrm{pH}$ for the localization of tyrosine hydroxylase. J Histochem Cytochem 29:844850.

Boivie J (1979) An anatomical reinvestigation of the termination of the spinothalamic tract in the monkey. J Comp Neurol 186:343-370.

Bullitt E (1990) Expression of $c$-fos-like protein as a marker for neuronal activity following noxious stimulation in the rat. J Comp Neurol 296:517-530.

Burstein R, Giesler GJ Jr (1989) Retrograde labeling of neurons in the spinal cord that project directly to nucleus accumbens or the septal nuclei in the rat. Brain Res. 497:149-154

Burstein R, Cliffer KD, Giesler GJ Jr (1987) Direct somatosensory projections from the spinal cord to the hypothalamus and telencephalon. J Neurosci 7:4159-4164.

Burstein R, Cliffer KD, Giesler GJ Jr (1990a) Cells of origin of the spinohypothalamic tract in the rat. J Comp Neurol 291:329--344.

Burstein R, Wang J, Elde RP, Giesler GJ Jr (1990b) Neurons in the sacral parasympathetic nucleus that project to the hypothalamus do not also project through the pelvic nerve-a double labeling study combining fluoro-gold and cholera toxin B in the rat. Brain Res 506: $159-165$.

Burstein R, Dado RJ, Giesler GJ Jr (1990c) The cells of origin of the spinothalamic tract of the rat: a quantitative reexamination. Brain Res 511:329-337.

Burton H, Craig AD (1983) Spinothalamic projections in cat, raccoon and monkey: a study based on anterograde transport of horseradish peroxidase. In: Somatosensory integration in the thalamus (Macchi G, Rustioni A, Spreafico R eds), pp 17-41. Amsterdam: Elsevier.

Carstens E, MacKinnon JD, Guinan MJ (1982) Inhibition of spinal dorsal horn neuronal responses to noxious skin heating by medial preoptic and septal stimulation in the cat. J Neurophysiol 48:981991.

Carstens E, Leah J, Lechner J, Zimmerman M (1990) Demonstration of extensive brainstem projections to medial and lateral thalamus and hypothalamus in the rat. Neuroscience 35:609-626.

Casale EJ, Light AR, Rustioni A (1988) Direct projection of the corticospinal tract to the superficial laminae of the spinal cord in the rat J Comp Neurol 278:275-286.

Cechetto DF, Saper CB (1988) Neurochemical organization of the hypothalamic projection to the spinal cord in the rat. J Comp Neurol 272:579-604.

Chang H-T, Ruch TC (1949) Spinal origin of the ventral supraoptic decussation (Gudden's commissure) in the spider monkey. J Anat 83 : $1-9$

Cliffer KD, Giesler GJ Jr (1988) PHA-L can be transported anterogradely through fibers of passage. Brain Res 458:185-191.

Cliffer KD, Giesler GJ Jr (1989) Postsynaptic dorsal column pathway of the rat. III. Distribution of ascending afferent fibers. J Neurosci 9 : 3146-3168.

Cohen SR, Melzack R (1985) Morphine injected into the habenula and dorsal posteromedial thalamus produces analgesia in the formalin test. Brain Res 359:131-139.

Craig AD Jr (1988) Cervical lamina I spinothalamic projections in the cat. Soc Neurosci Abstr 14:120.

Craig AD, Burton II (1985) The distribution and topographical organization in the thalamus of anterogradely-transported horseradish peroxidase after spinal injections in cat and raccoon. Exp Brain Res 58:227-254.

Craig AD Jr, Wiegand SJ, Price JL (1982) The thalamo-cortical projection of nucleus submedius in the cat. J Comp Neurol 206:28-48.

Cucchiaro JB, Uhlrich DJ, Sherman SM (1988) Parabrachial innervation of the cat's dorsal lateral geniculate nucleus: an electron microscopic study using the tracer Phaseolus vulgaris leucoagglutinin (PHA-L). J Neurosci 8:4576-4588.

Dado RJ, Giesler GJ Jr (1990) Afferent input to nucleus submedius in rats: retrograde labeling of neurons in the spinal cord and caudal medulla. J Neurosci 10:2672-2686.

de Olmos JS, Ebbesson SOE, Heimer L (1981) Silver methods for the impregnation of degenerating axoplasm. In: Neuroanatomical tracttracing methods (Heimer L, Robards MJ, eds), pp 117-170. New York: Plenum

Dostrovsky JO, Guilbaud G (1988) Noxious stimuli excite neurons in nucleus submedius of the normal and arthritic rat. Brain Res 460 $269-280$.

Dostrovsky JO, Guilbaud G (1990) Nociceptive responses in medial thalamus of the normal and arthritic rat. Pain 40:93-104.

Dutar P, Lamour Y, Jobert A (1985) Activation of identificd scptohippocampal neurons by noxious peripheral stimulation. Brain Res 328:15-21.

Duysens J, Dom R, Gybels J (1989) Suppression of the hindlimb flexor reflex by stimulation of the medial hypothalamus and thalamus in the rat. Brain Res 499:131-140.

Everitt BJ (1990) Sexual motivation: a neural and behavioural analysis of the mechanisms underlying appetitive and copulatory responses of male rats. Neurosci Biobehav Rev 14:217-232.

Everitt BJ, Cador M, Robbins TW (1989) Interactions between the amygdala and ventral striatum in stimulus-reward associations: studies using a second-order schedule of sexual reinforcement. Neuroscience 30:63-75.

Fabian RH, Coulter JD (1985) Transneuronal transport of lectins. Brain Res 344:41-48.

Faull RLM, Mehler WR (1985) Thalamus. In: The rat nervous system, Vol 1, Forebrain and midbrain (Paxinos G, ed), pp 129-168. Sydney: Academic.

Fields HL (1987) Pain. New York: McGraw-Hill.

Follett KA (1989) A telencephalospinal projection in the Tegu lizard (Tupinambis teguixin). Brain Res 496:89-97.

Gerfen CR, Sawchenko PE (1984) An anterograde neuroanatomical tracing method that shows the detailed morphology of neurons, their axons and terminals: immunohistochemical localization of an axonally transported plant lectin, Phaseolus vulgaris leucoagglutinin (PHA-L). Brain Res 290:219-238.

Heimer L, Alheid GF, Zaborszky L (1985) Basal ganglia: In: The rat nervous system, Vol 1, Forebrain and midbrain (Paxinos G, ed), pp 37-86. Sydney: Academic.

Holstege $G$ (1987) Some anatomical observations on the projections from the hypothalamus to brainstem and spinal cord: an HRP and autoradiographic tracing study in the cat. J Comp Neurol 260:98126.

Hosoya Y, Ito R, Kohno K (1987) The topographical organization of neurons in the dorsal hypothalamic area that project to the spinal cord or to the nucleus raphe pallidus in the rat. Exp Brain Res 66: 500-506.

Hunt SP, Pini A, Evan G (1987) Induction of c-fos-like protein in spinal cord neurons following sensory stimulation. Nature 328:632634.

Johnson GD, de C Nogueira Araujo GM (1981) A simple method of reducing the fading of immunofluorescence during microscopy. $\mathrm{J}$ Immunol Meth 43:349-350.

Jones EG, Burton H (1974) Cytoarchitecture and somatic sensory connectivity of thalamic nuclei other than the ventrobasal complex in the cat. J Comp Neurol 154:395-432.

Ju G (1984) Direct connections between hypothalamus and lumbar spinal cord in rabbits. Sci Sin 27:789-799.

Kai Y, Oomura Y, Shimizu N (1988) Responses of rat hypothalamic neurons to periaqueductal gray stimulation and nociceptive stimuli. Brain Res 461:107-117

Katter JT, Burstein R, Giesler GJ Jr (1991) The cells of origin of the spinohypothalamic tract in the cat. J Comp Neurol 303:101-112.

Keller A, White EL, Cipolloni PB (1985) The identification of thalamocortical axon terminals in barrels of mouse SmI cortex using 
immunohistochemistry of anterogradely transported lectin (Phaseolus vulgaris-leucoagglutinin). Brain Res 343:159-165.

Kenshalo DR Jr, Giesler GJ Jr, Leonard RB, Willis WD (1980) Responses of neurons in primate ventral posterior lateral nucleus to noxious stimuli. J Neurophysiol 43:1594-1614.

Kerr FWL (1975) The ventral spinothalamic tract and other ascending systems of the ventral funiculus of the spinal cord. J Comp Neurol 159:335-356.

Kita H, Kitai ST (1987) Efferent projections of the subthalamic nucleus in the rat: light and electron microscopic analysis with the PHA-L method. J Comp Neurol 260:435-452.

Krettek JE, Price JL (1977) The cortical projections of the mediodorsal nucleus and adjacent thalamic nuclei in the rat. J Comp Neurol 171: 159-191.

Lec CL, McFarland DJ, Wolpaw JR (1988) Retrograde transport of the lectin Phaseolus vulgaris leucoagglutinin (PHA-L) by rat spinal motoneurons. Neurosci Lett 86:133-138.

Lidsky TI, Manetto C, Schneider JS (1985) Consideration of sensory factors involved in motor functions of the basal ganglia. Brain Res Rev 9:133-146.

Lim CR, Garant DS, Gale K (1985) GABA agonist induced analgesia elicited from the lateral preoptic area in the rat. Eur J Pharmacol 107: 91-94.

Lima D, Coimbra A (1988) The spinothalamic system of the rat: structural types of retrogradely labelled neurons in the marginal zone (lamina I). Neuroscience 27:215-230.

Lumb BM, Wolstencroft JH (1985) Electrophysiological studies of a rostral projection from the nucleus raphe magnus to the hypothalamus in the rat and cat. Brain Res 327:336-339.

Lund RD, Webster KD (1967) Thalamic afferents from the spinal cord and trigeminal nuclei: an experimental anatomical study in the rat. J Comp Neurol 130:313-328.

Ma W, Peschanski M (1988) Spinal and trigeminal projections to the parabrachial nucleus in the rat: electron-microscopic evidence of a spino-ponto-amygdalian somatosensory pathway. Somatosens Res 5:247-257

Mahieux G, Benabid AL (1987) Naloxone reversible analgesia induced by electrical stimulation of the habenula in the rat. Brain Res 406: $118-129$.

McAllister JP, Wells J (1981) The structural organization of the ventral posterolateral nucleus in the rat. J Comp Neurol 197:271-301.

Mehler WR (1969) Some neurological species differences-a posteriori. Ann NY Acad Sci 167:424-468.

Miletic V, Coffield JA (1989) Responses of neurons in the rat nucleus submedius to noxious and innocuous mechanical cutaneous stimulation. Somatosens Mot Res 6:567-587.

Minderhoud JM (1967) Observations on the supraoptic decussations in the albino rat. J Comp Neurol 129:297-312.

Miyagawa T, Ando R, Sakurada S, Sakurada T, Kisara K (1986) Effects of tooth pulp stimulation on single unit activity of the amygdala in cats. Folia Pharmacol Japon 88:173-178.

Mizuno N, Takahashi O, Satoda T, Matsushima R (1985) Amygdalospinal projections in the macaque monkey. Neurosci Lett 53:327330.

Mokha SS, Goldsmith GE, Hellon RF, Puri R (1987) Hypothalamic control of nocireceptive and other neurones in the marginal layer of the dorsal horn of the medulla (trigeminal nucleus caudalis) in the rat. Exp Brain Res 65:427-436.

Morgan JI, Cohen DR, Hempstead JL, Curran T (1987) Mapping patterns of $c$-fos expression in the central nervous system after seizure. Science 237:192-197.

Olszewski J, ed (1952) The thalamus of the Macaca mullata. An atlas for use with the stereotaxic instrument. Basel: Karger.

Palestini M, Mariotti M, Velasco JM, Formenti A, Mancia M (1987) Medialis dorsalis thalamic unitary response to tooth pulp stimulation and its conditioning by brainstem and limbic activation. Neurosci Lett 78:161-165.

Paxinos G, Watson C (1986) The rat brain in stereotaxic coordinates, 2d ed. Sydney: Academic.
Peschanski M, Ralston HJ III (1985) Light and electron microscopic evidence of transneuronal labeling with WGA-HRP to trace somatosensory pathways to the thalamus. J Comp Neurol 236:29-41.

Peschanski M, Mantyh PM, Besson JM (1983) Spinal afferents to the ventrobasal thalamic complex in the rat: an anatomical study using wheat-germ agglutinin conjugated to horseradish peroxidase. Brain Res 278:240-244.

Richardson RT, DeLong MR (1988) A reappraisal of the functions of the nucleus basalis of Meynert. Trends Neurosci 11:264-267.

Ring G, Ganchrow D (1983) Projections of nucleus caudalis and spinal cord to brainstem and diencephalon in the hedgehog (Erinaceus europacus and Paraechinus aethiopicus): a degeneration study. J Comp Neurol 216:132-151.

Sandrew BB, Edwards DL, Poletti CE, Foote WE (1986) Amygdalospinal projections in the cat. Brain Res 373:235-239.

Schmued LC, Swanson LW, Sawchenko PE (1982) Some fluorescent counterstains for neuroanatomical studies. J Histochem Cytochem 30:123-128.

Schwanzel-Fukuda M, Morrell JI, Pfaff DW (1984) Localization of forebrain neurons which project directly to the medulla and spinal cord of the rat by retrograde tracing with wheat germ agglutinin. J Comp Neurol 226:1-20.

Shu SY, Peterson GM (1988) Anterograde and retrograde axonal transport of Phaseolus vulgaris leucoagglutinin (PHA-L) from the globus pallidus to the striatum of the rat. J Neurosci Meth 25:175-180.

Shyu KW, Lin MT (1985) Hypothalamic monoaminergic mechanisms of aspirin-induced analgesia in monkeys. J Neural Transm 62:285293.

Smith Y, Bolam JP (1989) Neurons of the substantia nigra reticulata receive a dense GABA-containing input from the globus pallidus in the rat. Brain Res 493:160-167.

Swanson LW (1987) The hypothalamus. In: Handbook of chemical neuroanatomy (Bjorklund A, Hokfelt T, Swanson LW, eds), pp 1124. Amsterdam: Elsevier.

Werner J, Bienek A (1985) The significance of nucleus raphe dorsalis and centralis for thermoafferent signal transmission to the preoptic area of the rat. Exp Brain Res 59:543-547.

White JC, Sweet WH (1969) Pain and the neurosurgeon: a forty year experience. Springfield: Thomas.

Willis WD Jr (1985) The pain system. Basel: Karger.

Willis WD Jr (1986) Ascending somatosensory systems. In: Spinal afferent processing (Yaksh TL, ed), pp 243-274. New York: Plenum.

Wouterlood FG, Groenewegen HJ (1985) Neuroanatomical tracing by use of Phaseolus vulgaris-leucoagglutinin (PHA-L): electron microscopy of PHA-L-filled neuronal somata, dendrites, axons and axon terminals. Brain Res 326:188-191.

Wozniak DF, Stewart GR, Finger S, Olney JW (1989a) Comparison of behavioral effects of nucleus basalis magnocellularis lesions and somatosensory cortex ablation in the rat. Neuroscience 32:685-700.

Wozniak DF, Stewart GR, Finger S, Olney JW, Cozzari C (1989b) Basal forebrain lesions impair tactile discrimination and working memory. Neurobiol Aging 10:173-179.

Yamada J, Otani K (1978) The spinoperiventricular fiber system in the rabbit, rat, and cat. Exp Neurol 61:395-406.

Yasui Y, Itoh K, Mizuno N (1987) Direct projections from the caudal spinal trigeminal nucleus to the striatum in the cat. Brain Res 408: 334-338.

Yu L-C, Han J-S (1989) Involvement of arcuate nucleus of hypothalamus in the descending pathway from nucleus accumbens to periaqueductal grey subserving an antinociceptive effect. Int J Neurosci 48:71-78.

Zahm DS, Zaborsky L, Alheid GF, Heimer L (1987) The ventral striatopallidothalamic projection: II. The ventral pallidothalamic link. J Comp Neurol 255:592-605.

Zemlan FP, Leonard CM, Kow I-M, Pfaff DW (1978) Ascending tracts of the lateral columns of the rat spinal cord: a study using the silver impregnation and horseradish peroxidase techniques. Exp Neurol 62: 298-334. 